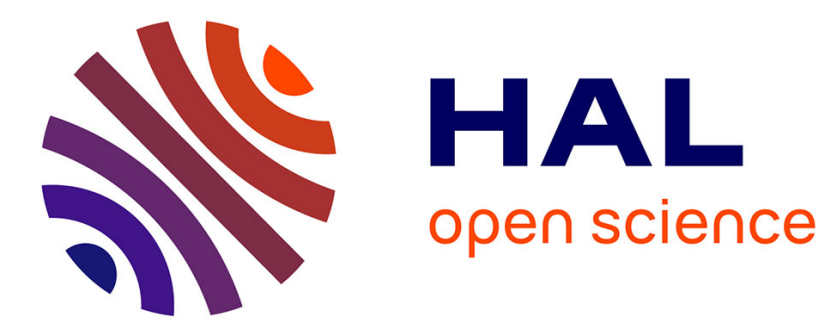

\title{
Engineering glucose oxidase for bioelectrochemical applications
}

\author{
Nicolas Mano
}

\section{To cite this version:}

Nicolas Mano. Engineering glucose oxidase for bioelectrochemical applications. Bioelectrochemistry, 2019, 128, pp.218-240. 10.1016/j.bioelechem.2019.04.015 . hal-02121438

\section{HAL Id: hal-02121438 \\ https://hal.science/hal-02121438}

Submitted on 9 May 2019

HAL is a multi-disciplinary open access archive for the deposit and dissemination of scientific research documents, whether they are published or not. The documents may come from teaching and research institutions in France or abroad, or from public or private research centers.
L'archive ouverte pluridisciplinaire HAL, est destinée au dépôt et à la diffusion de documents scientifiques de niveau recherche, publiés ou non, émanant des établissements d'enseignement et de recherche français ou étrangers, des laboratoires publics ou privés. 


\title{
Engineering Glucose Oxidase for Bioelectrochemical Applications
}

\author{
Nicolas Mano ${ }^{\mathrm{a}, \mathrm{b}}$ *
}

[a] Centre de Recherche Paul Pascal (CRPP), CNRS UMR 5031, 115 Avenue du Docteur Schweitzer, 33600 Pessac, France

[b] Univ. Bordeaux, CRPP, CNRS UMR 5031, 115 Avenue du Docteur Schweitzer, 33600 Pessac, France --- nicolas.mano@crpp.cnrs.fr

\begin{abstract}
There is still a growing interest in developing glucose sensors using glucose oxidase. Since 2012, over 1000 papers are published every year, while efficient commercial sensors exist on the market. Among those glucose sensors, few have been thought and well-engineered and do not solve the problems associated with glucose oxidase; among which the $\mathrm{O}_{2}$ sensitivity of the enzyme or the competition between $\mathrm{O}_{2}$ and redox mediators for GOx's electrons. Enzyme engineering has been employed to solve those issues but screening GOx in homogeneous solution with $\mathrm{O}_{2}$ as an electron acceptor is not suitable. Very few reports describe the specific reengineering of GOx for electrochemical applications and are the subject of this review. It starts with a brief presentation of glucose oxidase and presents the recent progress in glucose oxidase reengineering by highlighting the kind of engineering/mutations performed to increase its electron transfer rate to electrode surfaces and, to decrease its $\mathrm{O}_{2}$ sensitivity. In addition, the review highlights the need to develop new screening methods involving electrochemical probing, essential to develop the next generation of glucose sensors; specific to glucose, $\mathrm{O}_{2}$ independent, biocompatible and stable over 2 weeks.
\end{abstract}

Keywords: Glucose Oxidase, enzyme engineering, mediated electron transfer, electrochemical applications, biosensors, $\mathrm{O}_{2}$ sensitivity 


\section{CONTENTS}

$\begin{array}{ll}\text { 1. Introduction } & 3\end{array}$

2. Background 4

2.1. History 4

2.2. Sources 5

2.3. Overexpression of Glucose Oxidases 6

2.4. Overall Structure and Biochemical features 6

2.5. Glycosylation 8

2.6. Substrates and Inhibitors

2.7. FAD binding site 9

2.8. Substrate binding site 9

2.9. Electron pathways within Glucose Oxidase 10

2.10. Glucose oxidation mechanism 10

3. Redesigning Glucose Oxidase 12

$\begin{array}{ll}\text { 3.1. Increasing the rate of electron transfer } & 13\end{array}$

3.1.1. Rational or semi-rational strategy 13

3.1.1.1. Effect of the orientation 13

3.1.1.2. The use of nanoparticles $\quad 14$

3.1.1.3. Deglycosylation 16

3.1.1.4. Increasing the interaction between glucose oxidase $\quad 18$ and redox mediators.

3.1.2. Directed evolution 20

3.2. Decreasing the competitive effect of $\mathrm{O}_{2}$

3.2.1. Rational or semi-rational strategy 23

3.2.1.1. Cofactor redesign $\quad 23$

3.2.1.2. Enzyme engineering 23

3.2.2. Directed evolution 25

4. Conclusions and Outlook 26

5. Acknowledgments 29

6. References 30

7. Legends 


\section{Introduction}

Since its discovery in 1928, glucose oxidase (GOx) is still one of the most studied enzymes worldwide because of its various industrial applications.[1-3] GOx can be used for textile bleaching, in the food and baking industry[4-6] or for the production of gluconic acid[7,8] for example. The most well-known application of glucose oxidase is its use in daily and continuous glucose sensors for diabetes management.[9-12] GOx may also find applications in glucose $/ \mathrm{O}_{2}$ biofuel cell or self-power sensors.[13-18] The history of electrochemical glucose sensors is well documented and has been recently reviewed elsewhere.[11,12,19]

The greatest benefits of glucose oxidase over other sugars enzymes for bioelectrochemical applications[20] are its high specificity for glucose, low redox potential ( $-0.42 \mathrm{~V} v s . \mathrm{Ag} / \mathrm{AgCl}$ at $\mathrm{pH} 7.4)[21]$, and good thermostability. The three major drawbacks are the production of $\mathrm{H}_{2} \mathrm{O}_{2}$ during the oxidative half-reaction which can decrease the stability of enzymes, the competition between $\mathrm{O}_{2}$ and redox mediators for GOx electrons and the fact that the active redox center in native GOx is deeply buried within the protein preventing direct electron transfer (DET) to electrode surfaces.[22,23]

Various efforts have been put forward to solve those issues mainly focus on increasing electrode surfaces to enhance current/power densities and/or improving the electrical communication between the redox site of GOx and electrodes surfaces. So many and diverse strategies, more or less successful, have been reported that makes impossible a summary of those methods. Enzyme engineering has also been employed to improve the specific activity, glucose affinity and $\mathrm{O}_{2}$ sensitivity of GOx including ultrahigh-throughput screening.[24-28,29, 30] But, most of those efforts were performed in homogeneous solution using $\mathrm{O}_{2}$ as an electron acceptor and are not suitable for electrochemical applications. In addition, other parameters such as the interaction between GOx and redox mediators were not taken into account. Very 
few reports describe the specific reengineering of GOx for electrochemical applications and are the subject of this review.

This review is not a review on the use of glucose oxidase in biosensors and biofuel cells neither a review on the electrode materials or redox mediators developed to make these glucose sensors/anodes more efficient. Such topics have been summarized on various occasions. (Table 1) Rather, this is a review on glucose oxidase and how it can be rationally, or not, engineered to better serve glucose sensors/biofuel cells. This review will first start with a brief presentation of glucose oxidase, its property, and structure. Then, I will discuss the few reports aiming at reengineering glucose oxidase either by rational/semi-rational or directed evolution strategies for improved electrochemical applications. Particularly, the kind of engineering/mutations performed to increase the electron transfer rate between GOx and electrode surfaces and to decrease the $\mathrm{O}_{2}$ sensitivity of the enzyme will be presented.

\section{Background}

\subsection{History}

In 1928, Müller[31] discovered a glucose oxidase (GOx) in Aspergillus niger and Penicillium glaucum. He showed this enzyme could oxidize glucose to gluconic acid in presence of molecular oxygen and to a lesser degree could oxidize mannose and galactose. 10 years later, Franke et al.[32, 33] reported a purer and therefore 80 times more active glucose oxidase than that of Müller. They showed that oxygen was reduced to hydrogen peroxide and that indophenol could be used as hydrogen acceptors. The authors speculated this enzyme could be a flavoprotein. In the '40s, Coulthard et al.[34] were looking for the substance responsible for the antibacterial properties of Penicillium notatum in presence of glucose. During this work, they obtained a highly purified enzyme initially named penicillin A and later renamed notatin[35] to avoid the confusion with penicillin discovered by Fleming.[36] They 
demonstrated that notatin was only effective in presence of glucose and $\mathrm{O}_{2}$ and was identical to the enzyme discovered by Müller. Its bactericidal action was attributed to $\mathrm{H}_{2} \mathrm{O}_{2}$ produced during the oxidation of glucose. In parallel, two research groups identified an antibacterial substance from the culture media of $P$. notatum. Van Brugeen et al.[37, 38] named it Penicillin B. This new enzyme was considered different from notatin because penicillin B could oxidize glucose, mannose, galactose while Coulthard et al. reported that notatin could only oxidize glucose. In 1943, Kocholaty et al. named Penatin a newly identified enzyme.[39, 40] While the authors recognized the probable similarity between penatin and notatin, they doubted it could be identical with penicillin B. Finally the same year, Birkinshaw et al.[41] demonstrated that notatin, penatin, and penicillin B were the same enzymes identical to the GOx initially identified by Müller. The extensive work of Keilin later confirmed it and identified in 1946 the prosthetic group as an alloxazine adenine dinucleotide.[42] Later, further characterization of this enzyme and its properties[43] showed for example that GOx was highly specific to $\beta$-glucose rather than $\alpha$-glucose.[44]

\subsection{Sources}

GOxs have been identified in many sources, but few have been structurally and kinetically characterized. GOxs was found in insects[45-47], in alga[48], in fruits[49] but mainly in fungi including Aspergillus niger, [50-53] Aspergillus tubingesis,[54], A. Flavus[55], A terreus, [56] and various Penicillium species including $P$. sp[57], P. pinophilum[58], $P$. amagasakiense[59-63], $\quad P . \quad$ chrysogenum $[64,65], \quad P$. notatum $[35,40,66,67], P$. resticulosum[35], $P$. expansum[68], $P$. fellutanum[69], $P$. funiculosum[70-72], $P$. adametzii[73], P. vitale[74], P. variabile[75-78], from Alternaria alternata[79], from Botrytis cinerea[80], Phanerochaete chrysosporium[81, 82], Pleurotus ostreatus[83] and Talaromyces flavus.[84] Among those enzymes, A. niger and $P$. amagasakiense have been the most studied. 


\subsection{Overexpression of Glucose Oxidases}

To produce a higher amount of enzymes, recombinant GOxs were overexpressed in yeasts (Saccharomyces cerevisiae, Hansenula polymorpha[85] or Pichia pastoris) and bacteria (Escherichia coli). S. cerevisiae has been successfully used as a high yield production system for the heterologous production of $A$. niger [30, 52, 86-90]. However, it induces heterogeneous hyperglycosylation of the GOx (>67 wt $\%$ ) which displays a better thermostability but lowest activity compared to the native enzyme. Lehnert et al. have reported an hypoglycosylated GOx mutant but with low activity.[91] Alternatively, a glycosylated deficient strain $S$. cerevisiae $n g d 29$ has been used leading to lower and more homogeneous glycosylation than the native strain.[92] Much lower glycosylation state $(\sim 10 \mathrm{wt} \%)$ could be attained for GOx from A. niger [93-99], from P. amagasakiense[63] and from Penicillium variable P16[78] overexpressed in P. pastoris with an activity almost identical to the native enzyme. To avoid glycosylation, GOx from A. niger[100-102] and P. amagasakiense[103, 104] were overexpressed in E. coli. However, contrary to production in yeasts, GOx is produced in apo-form in bacteria and requires an additional reconstitution step with FAD to get the active holo-form. The main parameters of growth (carbon source, the effect of aeration/agitation/pH,..) and $\mathrm{GOx}$ production/purification/scale-up have been reviewed elsewhere.[2, 3,105]

\subsection{Overall Structure and Biochemical features}

Glucose oxidase ( $\beta$-D-glucose: oxygen 1-oxidoreductase, EC 1.1.3.4) belongs to the glucose-methanol-choline oxidoreductase family including for example cholesterol oxidase (EC1.1.3.6), pyranose oxidase (EC1.1.3.10) or methanol oxidase (EC 1.1.3.13) oxidizing primary and secondary alcohols. All those enzymes present a conserved domain which is involved in the binding of the adenosine diphosphate moiety of the FAD and usually, a conserved His residue acting as a base during the reductive half-reaction.[106-108] 
Crystallized GOx from A. niger (PDB: 1CF3[109], 1GAL[53], 3QVP[110]), $P$. amagasakiense (PDB: 1GPE)[109] are homodimeric glycoproteins with relative molecular masses ranging between 147 and $180 \mathrm{kDa}$ depending on the extent of the glycosylation. (Figure 1) The structure of $A$. niger and $P$. amagasakiense have been extensively compared and analyzed.[109, 111] Each monomer has a deeply-buried flavin adenine dinucleotide cofactor (FAD/FADH ${ }_{2}$ ) located at $\sim 15 \AA$ from the enzyme surface. The FAD is tightly but not covalently bound. Hydrophobic, salts bridges and hydrogen bonds connect the two monomers. A large deep pocket with a dimension of $\sim 10 \AA \times 10 \AA$ provides access to the active site, which is large enough to accommodate a substrate. GOx dimension is $\sim 60 \AA \times 52 \AA \times 77 \AA$, with a hydrodynamic diameter of $89 \AA[112]$ and displays an isoelectric point $\sim 4.3$. Tetrameric GOx with four identical subunits has also been reported for B. cinerea $(160 \mathrm{kDa})[80]$ and P. ostreatus (290 $\mathrm{kDa}$ [83] but X-rays structure have not been solved.

Direct comparison between the biochemical characterization of GOxs is made difficult because of the different experimental conditions. Most GOxs displays an optimum pH between 5 and 6 and an optimal temperature around $37^{\circ} \mathrm{C}$. Some GOxs differ in those properties. For example, GOx from $P$. notatum displays an optimum temperature at $45^{\circ} \mathrm{C}$ but is stable in a narrow range of $\mathrm{pH}$ 5-5.4. Reported $K_{M}$ values for glucose range between $1.34 \mathrm{mM}$ glucose for GOx from P. ostreatus[83], 5,7 mM for P. amagasakiense,[102] $6.2 \mathrm{mM} \mathrm{P.} \mathrm{pinophilum[58],}$ 10.5mM for P. notatum[67], 10.9mM for T. flavus[84], 30mM for A. niger and up to $38 \mathrm{mM}$ for P. chrysosporium.[81,82] Compared to GOx from A. niger, GOxs from Penicillium species exhibit more advantageous properties for glucose oxidation.[57-59,72] In particular, $P$. amagasakiense exhibits a six-fold higher substrate specificity and a four-fold higher catalytic rate constant than GOx from A. niger.[63] However, Penicillium species are less stable than the A. niger counterpart. 


\subsection{Glycosylation}

Glycosylation can vary between 11 and $30 \mathrm{wt} \%$ of the total molecular weight depending on the GOx species and the host choose to overexpress the enzyme. Eight potential Nglycosylation have been identified in A. niger among which at N43, N89, N161, N168, N258, N355, N388, and N473 (Figure 1).[52,113] The carbohydrate moiety is a high mannose and oligomeric polysaccharide attached through asparagine, serine or threonine residues.[114] In $P$. amagasakiense, seven out of the 8 glycosylation sites identified in A. niger are conserved. In both cases, N89 (N93 in P. amagasakiense) is an extended carbohydrate moiety forming a bridge between both monomers. This moiety is providing extra stability of the GOx. Deglycosylation is essential for the crystallization of GOxs.[115] By incubating GOx from $A$. niger with endoglycosidase $\mathrm{H}$ and $\alpha$-mannosidase, Kalisz et al. could cleaved $95 \%$ of the carbohydrate moieties with no effect on the three-dimensional structure or on the enzyme kinetic properties.[113] The remaining 5\% ( 2 kDa) corresponds to 8 mannose and $2 \mathrm{~N}$ acetylglucosamine. A similar decrease was observed for $P$. amagasakiense.[61, 102] For both species, the remaining carbohydrate chain, unaltered upon deglycosylation, corresponds to N89 or N93.[102]

\subsection{Substrates and Inhibitors}

The greatest advantage and characteristic of GOx is its high specificity to $\beta$-glucose.[44] GOxs species can oxidize other sugars such as D-galactose, D-mannose, 2-deoxy-D-glucose, and D-xylose but at a slower rate.[70, 102, 116-118] The main inhibitor is hydrogen peroxide which inactivates the enzyme by oxidizing key methionine residues.[119, 120]. Other inhibitors include gluconic acid[119] and divalent cations $\left(\mathrm{Cu}^{2+}, \mathrm{Cd}^{2+}, \mathrm{Hg}^{2+}, \mathrm{Pb}^{2+}\right)$ for concentration> 50 mM.[121, 122] The interaction of monovalent cations with GOx could lead to a compaction of the enzyme resulting in enhanced stability against thermal and urea denaturation. Such a 
stabilizing effect followed the Hofmeister series.[123] Below 1M, divalent cations such as $\mathrm{Ca}^{2+}$ or $\mathrm{Mg}^{2+}$ can stabilize the enzyme while above $2 \mathrm{M}$, they induce dissociation of the GOx.[124]

\subsection{FAD binding site}

At few exception, the FAD-binding site is almost identical in P. amagasakiense and A. niger. The active sites residues in A. niger include tyrosines (Y68 and Y515), threonine (T110), arginine (R512), asparagine (N514) and three histidines (H78, H516, and H559), all forming hydrogen bonds with the cofactor (Figure 2). In P. amagasakiense, T110 is replaced by S110, Y515 by W515 and H78 by Q78.[109] It is unknown if such substitutions are the reason for the difference in specificity/activity between both species. Among the two conserved catalytic histidines (His516/His559) in A. niger and (His520/His563) in P. amagasakiense, only one of the histidine (His516/H520) is found in all members of the GMC family. It highlights its crucial importance in the reductive half-reaction to help the formation/stabilization of the anionic superoxide species.

\subsection{Substrate binding site}

Because of the inherent difficulties in getting enzyme-substrate complexes, docking, molecular mechanics and quantum chemical studies were performed to give an insight into the position of glucose within the active site.[109,125] 12 hydrogen bonds and three hydrophobic contacts to three neighboring aromatic residues to FAD stabilize glucose. In A. niger, the $\mathrm{O} 1$ hydroxyl group of glucose is located at equidistance between H516 and H559. Glucose molecules form hydrogen bonds with Y68, N514, R512, H516, H559, T110 and are further stabilized by hydrophobic interactions with F414 and W426. (Figure 3) In P. amagasakiense, the involved residues are Y73, S114, F418, W430, R516, N518, H520, and H563. In this enzyme, reports showed that R516 and to a lesser extend N518 are critical amino acids for the binding of glucose.[126] 


\subsection{Electron pathways within Glucose Oxidase}

Because of the restricted size of the enzyme pocket, it has been hypothesized that the size of some redox mediators was too large to reach the active site pocket of GOx, implying that long-range electron transfer throughout the protein should take place. Alvarez-Icaza et al.[127] performed modeling studies using the X-rays structure of GOx from Aspergillus niger. [53] The authors identified three putative pathways linking the FAD to the enzyme surface. The first pathway end at R95 near the interface between the two monomers and may not be accessible for redox mediators, whatever their size/polarity. The second pathway emerges at D573 near the $\mathrm{C}$ terminus of the enzyme and was used by Hall et al. to immobilize GOx on a modified glassy carbon electrode.[128] Predictions indicated that the third pathway was the most probable even if it ends at C164 and is surrendered by N161 and N 168 when the enzyme is glycosylated. Electrons would leave the FAD to reach a T110 continuing to W111, then the side chain of E144, to H165 to finally reach C164.(Figure 4A) Interestingly, a similar pathway exists in GOx from $P$. amagasakiense (Figure 4B, in yellow). However, no experimental evidence is available to confirm the existence of such pathways.

\subsection{Glucose oxidation mechanism}

Deciphering the mechanism of glucose oxidation has been the subject of intense research. It is admitted that glucose oxidation follows a Ping-Pong Bi-Bi mechanism[129] since the 70's[130-134]. Since then, our understanding has considerably evolved, and several reviews have summarized the detailed kinetic mechanism of GOx, even though some questions remain unanswered.[108,135-137] The work of Klinman and co-workers [138-142] who studied in details the $\mathrm{O}_{2}$ reactivity of flavoproteins is of particular interest.[143-145]

Glucose oxidation (Figure 5) occurs in two sequential reductive (Eq 1) and oxidative half-reactions (Eq 2). In the reductive half-reaction, $\beta$-D-glucose is oxidized to D-glucono- $\delta$ lactone further non-enzymatically hydrolyzed to gluconic acid. In the oxidative half-reaction, 
molecular oxygen, the natural co-substrate of the enzyme, enter the active site after the release of D-glucono- $\delta$-lactone and is reduced to hydrogen peroxide.

Mechanistically, for the reductive half-reaction (Figure 6), glucose is first replacing a water molecule (W110) within the oxidized active site simultaneously with the departure of a proton from His516. This residue, acting as a Lewis base, is a key residue involved during the oxidative half-reaction.[141] Then a concerted hydride anion and proton transfer respectively from the C1-substrate to the N5-flavin and to His516 is occurring. A new molecule of water then replaced D-glucono- $\delta$-lactone. It results in transferring two protons and two electrons at the site of the reduced flavin and the protonated histidine. The proper acidity of the active site is presumably maintained by E412. A remote R224 could also play a role in promoting the electron/proton transfer from the glucose to the FAD.[146]

In the oxidative half-reaction, two protons and two electrons are transferred from the reduced FAD to molecular oxygen via two single electron transfer steps, yielding hydrogen peroxide and regenerating the oxidized state of the enzyme. In all GOx structures, a water molecule is present in the active site located $2.8 \AA$ from His516 (Figure 7). During the reaction of the reduced enzyme with $\mathrm{O}_{2}$, it may offer a preorganized binding site for the superoxide species. It would, therefore, be necessary that $\mathrm{O}_{2}$ diffuse to the active site and displaces the water molecule. Whether $\mathrm{O}_{2}$ reaches the active site by protein breathing[137] or through defined channels guiding $\mathrm{O}_{2}$ to the $\mathrm{C}(4 \mathrm{a})$ atom of the reduced flavin [147-149] as yet to be determined. Recent structural analysis has suggested that a non-polar site, near the protonated His, is likely to be a feature of flavoprotein oxidases and would be a critical feature to accommodate $\mathrm{O}_{2}$.[145] In GOx from A. niger, it would be V560 and V564 in P. amagasakiense. All experimental attempts to identify $\mathrm{O}_{2}$ within the active site, even by using chloride anions as a surrogate, have been unsuccessful so far.[110] After diffusion and binding of $\mathrm{O}_{2}$, the transfer of the first electron results in the formation of a thermodynamically unfavorable $\mathrm{O}_{2}^{-\bullet} /$ flavin semiquinone pair stabilized through electrostatic or hydrogen-bond by the positively charged His516. (Figure 8) 
The protonation state of His516 is crucial at this step. [26, 138, 142, 150, 151] Such stabilization prevents the accumulation of toxic reactive species and permits the transfer of a second electron/proton leading to the formation of $\mathrm{H}_{2} \mathrm{O}_{2}$. During this reaction, the rate-limiting step is the transfer of the first electron.

Wohlfahrt et al. summarized in details the kinetic with various quinone derivatives.[135] Modeling studies showed that the oxidative half-reaction occurs in two electron transfer steps. (Figure 9) The first step is a hydride anion transfer to one of the quinone, reorienting the substrate within the active site, followed by a proton transfer to His516. For redox mediators only able to exchange one electron at a time, the oxidative half-reaction occurs in multiple steps. This is only true if $\mathrm{O}_{2}$ does not compete with the redox mediator for glucose oxidase electrons.

\section{Redesigning Glucose Oxidase}

Most of the engineering work on glucose oxidase has been performed in homogeneous solution either to decipher the glucose oxidation mechanism or to tune the selectivity of the enzyme. Few reports describe the redesign of glucose oxidase by enzyme engineering for bioelectrochemical applications. Among those reports three strategies were adopted: rational or semi-rational strategies, directed evolution or a combination of those methods.[152-154] Rational or semi-rational strategies require the knowledge of the 3D structure of the enzyme while directed evolution do not, but will require a reliable screening process. In the following paragraphs is described the attempt to redesign GOx with the aim to increase the rate of electron transfer between GOx and the electrode surfaces and/or decrease the $\mathrm{O}_{2}$ sensitivity of the enzyme.

Most of the work has been reported with GOx from A. niger or P. amagsakiense and this review will be focused on those enzymes. We can note that a different glucose oxidase from Penicillium pinopilum[58] displaying a low $\mathrm{K}_{\mathrm{M}}$ for glucose $(6.2 \mathrm{mM})$ was used to build a 
glucose $/ \mathrm{O}_{2}$ biofuel cell to maximize the power density at low glucose concentration.[155] In presence of $5 \mathrm{mM}$ glucose concentration, the power density with the new enzyme was 3.1 fold higher than a biofuel cell prepared with GOx from A. niger.

\subsection{Increasing the rate of electron transfer}

One of the main difficulties in bioelectrochemistry is to properly connect enzymes onto electrodes surfaces to increase the rate of electron transfer. This is true for GOx but also for any enzymes. Electrons and holes can be tunneled over 14 $\AA$.[156, 157] The rate of electron transfer increases by 2.71 each time the distance between enzymes and electrodes is decreased by $0.8 \AA$. Shortening the distance between the redox centers of the enzyme and the electrode surface is, therefore, the easiest way to increase the rate of electron transfer. In direct electron transfer, it can only be done if the enzyme is properly oriented and/or if the enzyme is engineered to bring the redox center close to the electrode surface. In mediated electrode system, it can be done by using properly engineered redox mediators (gold nanoparticles, osmium redox polymer,..) splitting the distance that holes and electrons need to travel, and increasing the rate of tunneling. The following part presents various strategies employed to electrically connected GOx onto electrodes surfaces aiming at enhancing electron transfer rate.

\subsubsection{Rational or semi-rational strategy}

\subsubsection{Effect of the orientation}

It has been hypothesized that one of the shortest electron transfer route from the redox site of GOx to the enzyme surface exits at N577, near the C terminus.[127] Therefore, Hall et al.[128] proposed to orient GOx to the electrode surface via the $\mathrm{C}$ end of the protein. They produced a non-glycosylated GOx from $P$. amagasakiense[102] and added at the C-terminus 
an hexa histidine sequence to specifically orient the enzyme on nitrilotriacetic acid functionalized glassy carbon electrode. They measured a $350 \mathrm{~s}^{-1}$ electron transfer rate under $\mathrm{N}_{2}$ conditions and $160 \mathrm{~s}^{-1}$ in $\mathrm{O}_{2}$ conditions. The competition with $\mathrm{O}_{2}$ explained the difference in the rate constant. The authors hypothesized that the high electron transfer rate may be due to the bent conformation of the FAD within the enzyme upon immobilization on the electrodes surface. With the same philosophy, Chung et al.[158] have reported genetically engineered GOx mutants tagged with arginine for improved attachment to metal surfaces.

\subsubsection{The use of nanoparticles}

Metallic particles, including gold nanoparticles (AuNPs), are now used in bioelectrochemical systems to provide for a higher specific surface, better enzyme orientation, enhance electron transfer or a combination of each.[159, 160] Most of the reported work on GOx consists in the addition of metallic particles within polymeric matrixes[161] or the direct attachment of GOx on Pt [162] or gold particles[163, 164] to shorten the distance between the FAD/FADH ${ }_{2}$ and electrode surfaces. But, such methodologies do not allow the control of the amount of enzyme attached to the AuNps neither their specific orientation.

Willner et al. reported the first rational approach to the use of AuNps. Around the year 2000, they developed a strategy aiming at improving the electrical connection between enzymes and electrodes by aligning enzymes on electrodes surface by reconstituting apo-enzymes on FAD or PQQ/FAD based monolayers.[165-169] They extended their concept by incorporating non-diffusing and bounded nanoparticles which could act as a relay between enzymes and electrodes. In 2003, Xiao et al.[170] reported the reconstitution of an apo-GOx from A niger on $1.4 \mathrm{~nm}$ gold AuNP functionalized with FAD.(Figure 10A) This work is the first example allowing the specific and control immobilization of one, and only one AuNp, per enzyme.(Figure 10B) The electron transfer rate of the reconstituted bioelectrocatalyst was 5000 
per second, 7 fold higher than the native enzyme with its $\mathrm{O}_{2}$ natural co-substrate. This is the highest rate reported so far in the literature. But the oxidation of glucose (Figure 10C) under $\mathrm{N}_{2}$ saturated conditions occurred at very large overpotentials ( +0.7 V vs $\mathrm{Ag} / \mathrm{AgCl})$.

Holland et al. have taken an additional step forward allowing not only the control of the number of immobilized AuNps on GOx and their specific position on the enzyme. (Figure 11A) They were the first to attach their AuNps to the surface of GOx via protein re-engineering.[171] Glucose oxidase was genetically modified to display a free cysteine near its active site to ease the site-specific attachment of a modified gold nanoparticle to the enzymes, enabling DET between the enzyme and the electrode. The authors used an earlier develop double mutant GOx from A niger (T56V/T132S) overexpressed in S. cerevisiae and displaying better catalytic properties than the native enzyme.[172] They mutated to valine one free cysteine present near the active site of the enzyme (C521) to prevent unwanted AuNPs attachment. It resulted in the triple mutant (T56V/T132S/C521V). Cys residues were then introduced on 5 positions ranging from $13.8 \AA$ to $28.5 \AA$ from the FAD by site-directed mutagenesis. $1.4 \mathrm{~nm}$ maleimide-modified gold nanoparticle could then react with the different mutants. They observed a dramatic decrease in activities for all mutants. The most promising mutant $\mathrm{H} 447 \mathrm{C}$, with the shortest distance between the FAD and Cys, was tested electrochemically by drop casting modified GOx onto the gold electrode (Figure 11B). In the presence of $1 \mathrm{mM}$ glucose in $\mathrm{N}_{2}$ saturated buffer, the authors observed an onset of glucose oxidation at $-0.4 \mathrm{~V} v s . \mathrm{Ag} / \mathrm{AgCl}$, only $60 \mathrm{mV}$ more oxidizing than the $-0.46 \mathrm{~V} v s$. $\mathrm{Ag} / \mathrm{AgCl}$ redox potential of the $\mathrm{FAD} / \mathrm{FADH}_{2}$ at $\mathrm{pH}$ 7.9. Indicating that AuNps enable direct electrical connection to the electrode surface. In the two works cited above, experiments were performed under Ar. Therefore it is not clear if AuNps permits increasing so much the rate of electron transfer so it prevents/decreases the competitive reaction with $\mathrm{O}_{2}$. Finally, this strategy is considered to be DET in the literature. However, since gold particles are acting as a shuttle of electrons between the redox centers of the enzyme and the electrode surfaces, this author thinks it would rather be MET. 


\subsubsection{Deglycosylation}

Glycosylations act as an insulating membrane and increase the distance the electrons need to travel to reach the electrode surface. Deglycosylation permits shortening this distance and has only minor effects on GOx activity in homogeneous solution. $[53,61,103,113,115$, 150] In 1989, Kalisz et al.[173] reported a deglycosylated GOx from P. amagasakiense oxidizing glucose at $0 \mathrm{~V}$ vs. $\mathrm{Ag} / \mathrm{AgCl}$ on graphite electrode. Later, Gratzel et al.[174] reported the immobilization of a partially deglycosylated GOx from A. niger in combination with a ferrocene derivatives redox mediator on a graphite electrode. They observed a 100 fold increase in the second-order rate constant compared to a non-deglycosylated GOx, indicating a better electron transfer.

Courjean et al.[112] reported a purified and nearly fully deglycosylated GOx from $A$. niger. Upon immobilization on glassy carbon electrode, a strong and reversible peak attributed to the $\mathrm{FAD} / \mathrm{FADH}_{2}$ redox centers at $-0.49 \mathrm{~V}$ vs. $\mathrm{Ag} / \mathrm{AgCl}$ was observed. This signal could not be due to FAD impurities since the GOx was purified.[23] In presence of $45 \mathrm{mM}$ glucose, a current of $235 \mu \mathrm{A} . \mathrm{cm}^{-2}$ was reached in a $20 \mathrm{mM}$ phosphate buffer $\mathrm{pH} 7.4$ while no current was observed with the native and fully glycosylated GOx. Deglycosylation permits to efficiently decrease the distance between the redox centers of the GOx and the electrode surface, yielding an electrically connected GOx able to oxidize glucose. A closer look at the catalytic CV shows a half wave potential of $-0.4 \mathrm{~V}$ vs. $\mathrm{Ag} / \mathrm{AgCl}$, more oxidizing than expected. Therefore, it is not excluded that the catalysis observed is due in part by some FAD molecules leaving the redox centers and acting as a shuttle of electrons between the electrode and the enzyme. Particularly since a mixture of globular and butter-fly shaped GOx were observed by atomic force microscopy on the electron surface. While it is clear that native and glycosylated GOx cannot undergo DET, [12, 22, 23] whether DET is feasible or not with deglycosylated GOx is still the subject of intense debate.[175] 
To decrease the tunneling distance between GOx and redox mediators, Prévoteau et al.[176] immobilized deglycosylated GOx from A. niger within osmium based redox polymers on glassy carbon electrodes. Heller and co-workers pioneered osmium based redox polymers acting as a shuttle of electrons between the $\mathrm{FAD} / \mathrm{FADH}_{2}$ redox centers and the electrode surface.[177-180] It permits yielding electrically connected GOx in three-dimensional redox hydrogels whatever their orientation. It is done by creating an electrostatic adduct between negatively charged GOx and positively charged osmium polymer at $\mathrm{pH} 7$, which can be further cross-linked to offer better stability. The mobility of the osmium complexes that can collide by segmental collisions between oxidized and reduced state induces electron conduction within those hydrogels.[181-183]. The glucose oxidation current was $38 \%$ higher when deglycosylated GOx was used compared to the native GOx. But, the increase in current was because of a better interaction between the enzyme and the redox polymer leading to a more efficient hydrogel structure, rather than due to an increase in the rate of electron transfer between the GOx redox site and the osmium polymer.

To further explore the impact of glycosylations, different GOx with various degree of glycosylation, and resulting in different molecular weight, were produced by the same authors: GOx from $P$. amagasakiense overexpressed either in E. coli (132 kDa), in P. pastoris (155 $\mathrm{kDa})$, or overexpressed in P. pastoris and deglycosylated (139 kDa) and GOx from A. niger (158 kDa) which was used as a control.[103] All GOx showed the same activity in homogeneous solution. To find whether the charge and /or the size of the GOx affect the hydrogel structure and dictate the current, the authors modified electrodes with osmium based redox polymers and each GOx. They found none correlation between the magnitude of the current density and the size of the enzyme. The controlling parameter was the surface charge of the enzyme, regardless of its size. (Figure 12) The work cited in this paragraph illustrates that downsizing the GOx's dimension allows for a better electron transfer. But this increase in rate constant is not necessarily because of a decrease distance between the FAD/FADH 2 redox 
site and the redox mediators/electrode surface. It can be due to better binding between the GOx and the redox mediator.

\subsubsection{Increasing the interaction between glucose oxidase and redox mediators.}

In 2002, Cass et al.[94] genetically modified a recombinant GOx from A. niger with a peptide chain linked on one side at the $\mathrm{C}$ terminal and to a polylysine chain at the other end. (Figure 13) A positively and hydrophilic chain was chosen to avoid its folding onto the GOx, potentially affecting its native structure. With such a strategy, the authors expected to anchor more redox mediator to the mutant enzyme compared to a non-modified GOx by introducing a specific binding between them. The modified mutant exhibited the same kinetics characteristics than the native enzyme. Screen printed electrodes prepared with the new mutant displayed a two-fold increase in current at $50 \mathrm{mM}$ glucose and better stability compared to the native enzyme, illustrating a better interaction between the redox mediator and the mutant GOx.

While enzyme purification is a common practice in molecular biology/enzymology, it is not always the case in bioelectrochemistry. Gao et al.[184] investigated the effect of the purity of a commercial GOx from $A$. niger on the glucose oxidation current when osmium based redox polymers were used as redox mediators. In presence of $5 \mathrm{mM}$ glucose in an $\mathrm{O}_{2}$ saturated $\mathrm{pH} 7.2$ buffer at $37^{\circ} \mathrm{C}$, the oxidation current was three-fold higher when a purified GOx was used compared to a non-purified enzyme. This was explained by a better interaction between the purified GOx and the redox polymer allowing to maximize the electron transfer to the osmium complexes rather than to $\mathrm{O}_{2}$.

In order to further increase the interaction between osmium based redox polymers and GOx from $P$. amagasakiense, Suraniti et al.[104] rationally redesigned the entrance pocket of the enzyme. The authors found that while GOx from $P$. amagasakiense exhibited better kinetics than GOx A. niger in homogeneous solution, once immobilized within osmium based redox polymer, its glucose oxidation current was $35 \%$ lower. They attributed this difference by the 
absence of negatively charged amino acids around the entrance pocket of GOx from $P$. amagasakiense compared to A. niger.(Figure 14) They speculated that negatively charged residues in $A$. niger permitted increasing the electron transfer by favoring the interaction between the positively charged osmium complexes and the enzyme. Therefore, the author redesigned the entrance pocket of GOx from $P$. Amagasakiense overexpressed in E.coli to make it more negative. Site-directed mutations and their combination were performed on 4 residues; K424, Q75, Q184, and G423 either with E or D to keep the size of the amino acid constant. All mutants displayed the same activity in homogeneous solution. Modified electrodes were prepared and tested electrochemically with $1 \mathrm{mM}$ glucose in a $20 \mathrm{mM}$ phosphate $\mathrm{pH} 7$ at $37^{\circ} \mathrm{C}$, under $\mathrm{Ar}$ and $\mathrm{O}_{2}$. Only the K424E mutation resulted in a significant enhancement in the current. Under Ar, the oxidation current for an electrode made with the K424E mutant increased 2.4 fold and 1.4 fold under $\mathrm{O}_{2}$ compared to the native enzyme. The substitution of a $\mathrm{K}$ by a $\mathrm{E}$ in position 424 placed a negative charge next to the entrance of the active site increasing the interaction between the positively charges osmium and the enzyme. Those results illustrate that by redesigning the entrance pocket of the enzyme and by making it more negative, one can get a better interaction between the Os and the GOx, thereby enhancing the rate of electron transfer. But, this study illustrates that this increase is still not fast enough to compete with $\mathrm{O}_{2}$.After such redesign, the current was 1.8 fold higher for an electrode made with GOx P. amagasakiense compared to GOx A. niger. More attempts to increase the negative charges around the entrance pocket led to a sharp decrease in current density, indicating that 424 was a key and unique position. This work suggest that there may be a pathway linking the FAD to the outer surface of the enzyme through position 424. Such mutant was also used with success with other positively charged redox mediators.[185] This work shows that minor remodeling can have a huge impact on the current and that not all effort should be dedicated to doing mutations near the active site. It highlights that the interaction between redox mediators and enzyme must be carefully engineered. 
In 2018, Arango Gutierrez et al.[186] combined theoretical and docking modeling, to study the interaction of three redox mediators, two quinone diimine redox mediators differing in their polarity and ferrocenemethanol, within the active site of GOx. They used a sextuple mutant previously discovered[186] and performed saturated site-directed mutation on position 414. Four beneficial mutations (Y, M, L, V) and particularly the substitution of I by Y lead to a 4.8 fold increase activity for the more polar redox mediator. They showed that the two quinone diimine mediators preferentially bind in the active site of the GOx, $3.5 \AA$ away from the N5 atom of the FAD. They concluded that position 414 modulates the electron shuttling from the FAD to the redox mediators depending on their size/polarity. (Figure 15)

\subsubsection{Directed evolution}

In 2012, Holland et al. rationally redesigned a glucose oxidase for improved catalytic activity and stability by combining the benefits of GOx from A. niger and GOx from $P$. amagasakiense.[172] By comparing their gene, they identified 17 residues differing between the two GOx species, particularly between the FAD-binding region and their active site. 15 residues selected in A. niger were subjected to site-directed mutation or saturation mutagenesis to mirror comparable residues in P. amagasakiense. A library of 4800 mutants was obtained among which 1200 were first screened colorimetrically than electrochemically because electrochemical probing on 4800 mutnats would be to lenghty. Electrochemical experiments were performed by recording the reduction of $\mathrm{H}_{2} \mathrm{O}_{2}$ on a Pt electrode poised at $+600 \mathrm{mV} v s$. $\mathrm{Ag} / \mathrm{AgCl}$ and immersed in a buffer containing GOx. Four mutants (T110SS, T110S/T34V, V20Y, T110S/V20Y) displayed a 3 to 4.5 fold improvement in the catalytic rate constant as determined electrochemically. The authors attributed the highest activity recorded for the T110S mutant by the replacement of the threonine by a smaller residue reducing the steric 
hindrance near the isoalloxazine ring and therefore favoring the stabilization of the peroxy adduct.(Figure 16) The authors did not excluded either that such mutation may affect glucose oxidation since it has been hypothesized that T110S could be a ligand for the binding of glucose.[125] The effect of the V20Y and T34Y mutations are unknown. This work illustrates that electrical connection has been improved but concomitant with an improved $\mathrm{O}_{2}$ reduction. It also demonstrates that electrochemical screening is a valuable tool to identify new improved mutants but is, today, a lengthy process and unsuitable for the screening of thousands of mutants.

Schwaneberg et al.[90] reported the first overall strategy aiming at tailoring GOx from A. niger overexpressed in S. cerevisiae for electrochemical applications. They first developed a screening system in homogeneous solution based on the detection of gluconic acid rather than $\mathrm{H}_{2} \mathrm{O}_{2}$. Therefore, this method allows the screening of GOxs without using $\mathrm{O}_{2}$ as an electron acceptor. They identified a mutant I94V which was 1.3 times more active for glucose oxidation but was 1.5 fold more active for $\mathrm{O}_{2}$ consumption than the WT GOx.(Figure 17) One year later[187], they developed a mediated screening system for the directed evolution of GOx in homogeneous solution in 96 well screening plate with ferrocenemethanol as a redox mediator. Among the 4000 screened GOx mutants, a double mutant (T30S/I94V) exhibited a 1.9 times increase in enzymatic activity in presence of the redox mediator, increased thermostability and $\mathrm{pH}$ stability at basic $\mathrm{pH}$ when compared to the native WT, while $K_{M}$ for glucose remained unchanged. But, the double mutant exhibits the same oxygen consumption when compared to the wild type GOx. They further characterized the electrochemical properties of this new mutant by embedding it in a poly(vinylferrocene-co-2-hydroxyethylmethacrylate) redox polymer.[188] In a deaerated $100 \mathrm{mM}$ phosphate buffer $\mathrm{pH} 7$ containing $5 \mathrm{mM}$ glucose, the current density at $+0.5 \mathrm{~V}$ vs $\mathrm{Ag} / \mathrm{AgCl}$ of the mutant electrode was $23 \%$ higher compared to an electrode modified with the native WT and, $10 \%$ higher at $1 \mathrm{mM}$ glucose. Better interaction between the redox polymer and the GOx mutant explained such a difference. This result shows a great difference 
between the efficiency of glucose oxidation in solution and on the electrode surface illustrating the difficulty to predict the behavior of an immobilized enzyme from the data obtained in homogeneous solution.

\subsection{Decreasing the competitive effect of $\mathrm{O}_{2}$}

Competition between $\mathrm{O}_{2}$ (eq 1) and redox mediators (RM-eq 2) as electrons acceptor during the oxidative half-reaction is one of the main issues to solve, particularly since harmful $\mathrm{H}_{2} \mathrm{O}_{2}$ is produced.

$$
\begin{aligned}
& \mathrm{GOx}^{-\mathrm{FADH}_{2}}+\mathrm{O}_{2} \rightarrow \mathrm{GOx}-\mathrm{FAD}+\mathrm{H}_{2} \mathrm{O}_{2} \\
& \mathrm{GOx}_{-}-\mathrm{FADH}_{2}+(2 / \mathrm{x}) \mathrm{RM}_{(\mathrm{OX})} \rightarrow \mathrm{GOx}-\mathrm{FAD}+(2 / \mathrm{x}) \mathrm{RM}_{(\mathrm{RED})}+2 \mathrm{H}^{+}
\end{aligned}
$$

(where $\mathrm{x}=1$ or 2 is the number of electrons collected by the oxidized redox mediator)

In glucose oxidase based sensors, variations in $\mathrm{O}_{2}$ concentrations may lead to erroneous glucose measurements.[189] In glucose/ $\mathrm{O}_{2}$ biofuel cells, it may result in a decrease of power density because of $\mathrm{O}_{2}$ depletion at the cathode. Various strategies were proposed to decrease the competitive effect of $\mathrm{O}_{2}$. For example, by tuning the thickness and composition of redox hydrogels[190, 191], by using enzymatic scavenging systems,[192-195] or by tuning electrodes geometry and size.[196-199] But, most of the efforts have been essentially directed to the design of new redox mediators or the improvement of enzymes immobilization to capture the $\mathrm{FADH}_{2}$ electrons more rapidly than $\mathrm{O}_{2}$. Enzyme engineering is an alternative strategy to decrease the $\mathrm{O}_{2}$ sensitivity of GOx but has only be used in homogeneous solution to decipher the oxidative half-reaction mechanism. Below is discussed the few reports aiming at rationally redesigning $\mathrm{O}_{2}$ insensitive GOx for electrochemical applications. 


\subsubsection{Rational or semi-rational strategy}

\subsubsection{Cofactor redesign}

Cofactor redesign consists in replacing the natural flavin with an unnatural one. Klinman et al. used this strategy with GOx from A. niger to probe the $\mathrm{O}_{2}$ effect during the oxidative half-reaction.[141] They showed that by substituting by chloride the methyl groups in position 7 and 8 in the natural flavin, the $K_{\mathrm{M}}\left(\mathrm{O}_{2}\right)$ was 25 fold higher compared to the native GOx. With the aim to decrease the competitive effect of $\mathrm{O}_{2}$, Tremey et al. used this flavin analog to elaborate GOx bioelectrode.[200, 201] Figure 18 is the 6 steps protocol used to replace the natural flavin with the unnatural analog; 7,8-dichloro-FAD. The authors prepared modified electrodes by embedding the new analog within osmium based redox polymers.[201] Figure 19 shows the dependence of the normalized oxidation current density on the glucose concentration for electrodes modified with native GOx (triangles) and 7,8-dichloro-FAD-GOx (circles). As seen for glucose concentration $<10 \mathrm{mM}$, the current density for the 7,8-dichloroFAD-GOx electrode is higher compared to the native enzyme and almost independent of the concentration of $\mathrm{O}_{2}$. The $\mathrm{O}_{2}$ sensitivity is decreased by $90 \%$ while the electron transfer rate is increased 1.3 fold. Since the unnatural GOx is less sensitive to $\mathrm{O}_{2}$, the electrons generated upon the oxidation of glucose are captured by the redox polymer rather than by $\mathrm{O}_{2}$. Cofactor replacement is a valuable strategy to tune the reactivity of GOx since a large quantity of apoenzyme can be produced easily, but is a lengthy process.

\subsubsection{Enzyme engineering}

Sode et al. were the first to report a genetically engineered recombinant GOx in E. coli less sensitive to $\mathrm{O}_{2}$ and its used in glucose sensors. The authors successfully redesigned $\mathrm{O}_{2}-$ insensitive frucosyl amino acid oxidase[202] and fructosyl peptide oxidase[203] by identifying and performing mutations on the amino acids responsible for the electron transfer to $\mathrm{O}_{2}$. They 
highlighted that the pathway for electron transfer to redox mediators was distinct from the one to $\mathrm{O}_{2}$. Based on this success, the same method was applied to GOxs. The authors first identify the amino acids that would interact with $\mathrm{O}_{2}$ during the oxidative half-reaction. Then the $\mathrm{X}$-rays structure of cholesterol oxidase (PDB: $1 \mathrm{mxt}$ )[204] obtained in presence of $\mathrm{O}_{2}$ was used as a template to build corresponding models of GOx from A. niger and $P$. amagasakiense with $\mathrm{O}_{2}$. (Figure 20) Superimposition structures of GOxs and $\mathrm{ChOx}$ respectively revealed eight and five potential residues involved during the oxidative half-reaction with $\mathrm{O}_{2}$ for $P$. amagasakiense and A. niger. They performed rational alanine substitution on those residues.[205] Among those mutants, S114A for $P$. amagasakiense and T110A for A. niger[206] displayed 6.6 and 12.3-fold reduced $\mathrm{O}_{2}$ consumption. Because of the advantageous kinetic of $P$. amagasakiense, they further combined S114A with F355A, the second best mutant obtained by alanine substitution, and performed saturation mutagenesis on this position. The most promising mutant S114A/F355L was $88 \%$ less sensitive to $\mathrm{O}_{2}$ than the native $\mathrm{GOx}$ and was further tested electrochemically.[207] The double mutant and the WT were immobilized on glassy carbon electrodes with photoreactive polyvinyl alcohol. The effect of $\mathrm{O}_{2}$ on the glucose oxidation was tested at $25^{\circ} \mathrm{C}$ in a $100 \mathrm{mM}$ phosphate buffer $\mathrm{pH} 7$ using methoxy methylphenazinium methylsulfate as a redox mediator. In presence of $1 \mathrm{mM}$ glucose, the double mutant was 5 times less sensitive to $\mathrm{O}_{2}$ than the WT compared to anaerobic conditions but its absolute current was significantly lower than the WT.(Figure 21) This work illustrates that introducing mutations within the putative residues involved in the oxidative half-reaction allow engineering a GOx less sensitive to $\mathrm{O}_{2}$. But, this work points out that such mutation affects the reductive halfreaction and is responsible for a decrease in enzyme activity.

In choline oxidase, Orville et al.[208] identified V564, a non-polar residue guiding oxygen near the $\mathrm{C}(4 \mathrm{a})$ atom of the reduced flavin. Substitution of $\mathrm{V}$ into A or T results in a 50 fold decrease in the oxidative half-reaction. After analysis of the X-rays structure of Penicillium amagasakiense, Tremey et al.[209] identified a similar Valine $\sim 6 \AA$ from the Flavin and $\sim 7 \AA$ 
from His 520, which provides a positive charge for $\mathrm{O}_{2}$ activation (Figure 22). After screening in homogeneous solution with ferrocemethanol, the best $\mathrm{O}_{2}$ insensitive mutant was obtained when V was replaced by S. Detailed kinetic analysis showed that only the oxidative halfreaction was affected upon this mutation compared of the native GOx while the reductive halfreaction remained unaffected. They prepared modified electrodes with the new mutant and osmium redox hydrogels. In presence of $2 \mathrm{mM}$ glucose and under 1 atm $\mathrm{O}_{2}$, the current density for the mutant electrode was $27 \%$ higher than an electrode made with the native enzyme. The authors proposed that the substitution of the non-polar valine by a polar serine prevents the diffusion of $\mathrm{O}_{2}$ and/or the stabilization of the peroxy adduct, without affecting the glucose oxidation. Because of the limited quantity of hydrogen peroxide produced, the modified electrodes were 4.7 fold more stable compare to an electrode made with a native GOx. However, as seen in Figure 22 (red circles), 25\% of the electrons were still lost to the redox mediators. To further improve the system, the authors combined this mutation with the K424E mutation near the entrance pocket of the active site (blue squares). As illustrated in Figure 22, the double mutant $\mathrm{K} 424 \mathrm{E}-\mathrm{V} 464 \mathrm{~S}$ is independent of $\mathrm{O}_{2}$ over the entire glucose concentration range. These results suggest that during the oxidative half-reaction, the amino acids involved in transferring the electrons to the redox polymer differ from those involved in the transfer to $\mathrm{O}_{2}$. The double mutant combine enhances electron transfer because of the negatively charged glutamic acid at the entrance of the active site pocket while minimizing the influence of $\mathrm{O}_{2}$ because of the presence of a polar serine near the FAD.

\subsubsection{Directed evolution}

The Schwaneberg's group reengineered glucose oxidase by combining random and saturated sites directed mutagenesis using ABTS or quinone diimine as redox mediators (Figure 17).[210] In the first random evolution strategy, they identified 4 residues (A173T, A332S, 
F414L, V560A) with either increases activities with ABTS (A173T, F414L) or decrease $\mathrm{O}_{2}$ activity (A332S, V560A). In the second step of saturated sites directed mutagenesis on those 4 positions, they identified key mutations leading to an increase mediator or decrease $\mathrm{O}_{2}$ activities. Positions 173 and 332 contribute to increasing activities with the mediator and oxygen, and the reasons have yet to be explained. Substitutions (L/P/T/W/Q) in V560 showed a decrease in $\mathrm{O}_{2}$ activity while maintaining the mediator activity. A similar result has been observed by Tremey et al. with GOx from P. amagasakiense.[209] Substitutions in 414 either lead to a reduced $\mathrm{O}_{2}$ activity $(\mathrm{F} 414 \mathrm{M})$ or improved mediator activity (F414L/V/I). F414 is 8.2 $\AA$ above the FAD and stabilized glucose with hydrophobic interactions within the active site during the reductive half-reaction. The authors concluded that a difference in flexibility/size of the side chain of the residues may alter the binding efficiency of the redox mediator, once glucose has been oxidized. Combination of those mutations with the I94V and T30V mutations previously discovered led to a sextuple mutant (I94V, T30V, A173V, A332S, F414I, V560T) with a significant 5.7 fold reduced activity for $\mathrm{O}_{2}$ and a 6.4 fold increases activity for glucose oxidation.[211]

\section{Conclusions and Outlook}

Between 1968 and 2019, more than 15000 papers and 4800 patents have been published on glucose oxidase and its use. Since 2012, over 1000 papers per year are published on glucose sensors using glucose oxidase, while efficient commercial sensors exist on the market, some of them even operating for 14 days.[11] We can legitimately ask ourselves whether we really needs developing glucose sensors and for what purpose. It is even truer as the systems proposed today are more and more complex, without however solving the problems of $\mathrm{O}_{2}$ sensitivity, stability or biocompatibility, for example. In the 1960 s to 1980 s, two to three ingredients including an enzyme, a redox mediator and a protective membrane providing biocompatibility 
and/or controlling the mass transport of glucose composed most of the glucose sensors. Nowadays, among the countless GOx sensors reported every year, few have been carefully thought and well-engineered. Like a cooking recipe, we can find in the literature glucose oxidase based sensors comprising up to 8 or 9 ingredients including various particles, membranes, electrode materials,...making the manufacture of those sensors complicated, expensive, long and that will probably never be industrialized. In addition, new enzymes such as PQQ-GDH or FAD-GDH are convincing commercial alternatives to glucose oxidase.[19, 212-219] Unfortunately, this tendency to complicate simple system is found with these new enzymes.

But glucose oxidase still has a bright future ahead of because its advantages exceed its disadvantages. Various protein engineering tools have been used to circumvent those limitations. But screening in solution the properties of GOx so it displays the same properties once immobilized is unreliable and, even worse when $\mathrm{O}_{2}$ is utilized as an electron acceptor.

In homogeneous solution, substrates, redox mediators and enzymes are all free in solution. Here, the reaction takes place in the whole reaction volume, and no concentration profiles are encountered. When an enzyme is immobilized on an electrode surface, many of its properties might change. It is not unreasonable to think the adsorbed enzyme will partially change its conformation, which might change, either for better or for worse, the reactivity towards substrate and/or redox mediator, stability, tolerance towards other chemical species, etc. In addition, the binding between the redox mediator and the enzyme should be taken into account. In homogeneous solution, free redox mediators will approach the enzyme at an optimum contact point, while immobilized mediators might be hindered from doing so. Concentrations gradients may appear when an enzyme is immobilized onto an electrode surface. If only a thin layer of redox mediator is electrochemically active, the current measured electrochemically will therefore be lower than expected from the measurement in homogeneous solution with the same redox mediator. These are some of the reasons why it is almost 
impossible to anticipate the behavior of an immobilized enzyme based on homogeneous screening. A general engineering approach towards an efficient immobilized glucose oxidase for improved electrochemical applications has not been pursued so far, at the exception of the reports examined in this review, and is needed to develop the next generation of glucose sensors, biocompatible and stable for over 2 weeks.

Table 2/Figure 23 summarize the few reports aiming at reengineering GOx for improved electrochemical applications and discussed in this review. A critical step has been taken by screening GOx with redox mediator in homogeneous solution. But, as seen in this review with the work of $\mathrm{Zhu[187]} \mathrm{and} \mathrm{Yu}$ [188] for example, the efficiency of glucose oxidase is lower upon immobilization on electrodes surface compared to homogeneous condition. It confirms that predicting the effect of a mutation obtained in homogeneous solution once immobilized onto an electrode surface remains totally elusive. Electrochemical screening in homogeneous solution in presence[220] or absence of redox mediators[172] proved to be feasible but is a lengthy process and cannot be used for high throughput screening. While it is clear that mutations on positions V560 in A. niger and V564 in P. amagasakiense have a significant impact on the $\mathrm{O}_{2}$ sensitivity of GOxs, the nature of the amino acid to be substituted depends on the redox mediator used. In addition, mutations alone on position 560 or 564 do not totally shut down the $\mathrm{O}_{2}$ effect and has to be associated with additional mutations aiming at increasing the interaction between the redox mediators and the GOx. Whether $\mathrm{O}_{2}$ reach the active site by protein breathing or through defined channels to attack the reduced flavin remains to be answered.

Rational reengineering of immobilized GOx has been successfully achieved by Tremey et al.[209] by identifying the residues involved in the binding of redox mediators. But as seen in Figure 23, the amino acids involved in the binding of the redox mediators depend on the nature of the redox mediator. There is, right now, no clear rule to predict which residues should be mutated to improve the binding of redox mediators. The choice of the redox mediator and 
its redox potential are crucial as it needs to compete successfully with $\mathrm{O}_{2}$ for GOx electrons. A rational strategy would consist in identifying by modelling/docking the residues involved in the binding of the redox mediator and tailored those amino acids on demand in function of its size, polarity, charge, redox potentials,... Increasing the binding efficiency will improve the electron transfer rate and the stability.

Ideally, rational redesign should use engineering techniques to improve the specific activity, $\mathrm{O}_{2}$ sensitivity, redox mediator interaction without compromising the enzyme stability. About the substrate affinity, a reduction of the apparent $\mathrm{K}^{\prime}{ }_{\mathrm{M}}<5 \mathrm{mM}$ (i.e the value obtained after GOx immobilization) may be useful for biofuel cells while a $\mathrm{K}_{\mathrm{M}}{ }^{\prime}>25 \mathrm{mM}$ is desired for self-powers system or glucose sensors. Enzyme engineering may not be needed to tune $\mathrm{K}^{\prime}{ }_{\mathrm{M}}$ as alternative approaches can be used such as the careful choice of redox mediators and/or mass transport controlling membrane. Long-term stability and biocompatibility are the two biggest engineering challenges to address. This calls for the combination of protein engineering skills with expertise on redox mediator/polymer synthesis and electrochemistry, in combination with modelling/docking studies. The biggest technological challenge, and mandatory, is the development of screening systems with immobilized enzymes and redox mediators combining electrochemical probing, to be as close as possible from the final applications. This field

remains almost unexplored at the exception of one study by Bartlett et al.[221] Directed evolution should not be discarded either. But the production of an already functional GOx in E.coli would be great advance in combination with a high throughput electrochemical screening of immobilized enzymes/redox mediators.

\section{Acknowledgments}

The author thanks his present and past collaborators for their contribution in reengineering glucose oxidase for electrochemical applications. 


\section{References}

[1] C.M. Wong, K.H. Wong, X.D. Chen, Glucose oxidase: natural occurrence, function, properties and industrial applications, Appl. Microbiol. Biotechnol . 78 (2008) 927-938.

[2] S.B. Bankar, M.V. Bule, R.S. Singhal, L. Ananthanarayan, Glucose oxidase--an overview, Biotechnol. Adv., 27 (2009) 489-501.

[3] M.K. Dubey, A. Zehra, M. Aamir, M. Meena, L. Ahirwal, S. Singh, S. Shukla, R.S. Upadhyay, R. Bueno-Mari, V.K. Bajpai, Improvement Strategies, Cost Effective Production, and Potential Applications of Fungal Glucose Oxidase (GOD): Current Updates, Front. Microbiol., 8 (2017).

[4] A. Bonet, C.M. Rosell, P.A. Caballero, M. Gómez, I. Pérez-Munuera, M.A. Lluch, Glucose oxidase effect on dough rheology and bread quality: A study from macroscopic to molecular level, Food Chem., 99 (2006) 408-415.

[5] A.G. Cruz, W.F. Castro, J.A.F. Faria, P.C.B. Lollo, J. Amaya-Farfán, M.Q. Freitas, D. Rodrigues, C.A.F. Oliveira, H.T. Godoy, Probiotic yogurts manufactured with increased glucose oxidase levels: Postacidification, proteolytic patterns, survival of probiotic microorganisms, production of organic acid and aroma compounds, J. Dairy Sci., 95 (2012) 2261-2269.

[6] Z. Jiang, B. Ooraikul, Reduction of nonenzymatic browing in potato chips and french fries with glucose oxidase, J. Food Process. Preserv., 13 (1989) 175-186.

[7] J.I. Reyes-De-Corcuera, H.E. Olstad, R. García-Torres, Stability and Stabilization of Enzyme Biosensors: The Key to Successful Application and Commercialization, Ann. Rev. Food Sci.Technol., 9 (2018) 293-322.

[8] A. Savas, G.M. Igor, Gluconic Acid Production, Recent Patents on Biotechnology, 1 (2007) 167-180. 
[9] A. Heller, B. Feldman, Electrochemistry in Diabetes Management, Acc. Chem. Res., 43 (2009) 963-973.

[10] A. Heller, B. Feldman, Electrochemical glucose sensors and their applications in diabetes management, Chem. Rev., 108 (2008) 2482-2505.

[11] T. Bobrowski, W. Schuhmann, Long-term implantable glucose biosensors, Curr. Opin. Electrochem., 10 (2018) 112-119.

[12] P. Bollella, L. Gorton, Enzyme based amperometric biosensors, Curr. Opin. Electrochem., $10(2018)$ 157-173.

[13] D. Leech, P. Kavanagh, W. Schuhmann, Enzymatic fuel cells: Recent progress Electrochim. Acta., 84 (2012) 223-234.

[14] M. Falk, C.W. Narváez Villarrubia, S. Babanova, P. Atanassov, S. Shleev, Biofuel Cells for Biomedical Applications: Colonizing the Animal Kingdom, ChemPhysChem, 14 (2013) 2045-2058.

[15] M. Rasmussen, S. Abdellaoui, S.D. Minteer, Enzymatic biofuel cells: 30 years of critical advancements, Biosens. Bioelectron., 76 (2016) 91-102.

[16] N. Mano, A. de Poulpiquet, $\mathrm{O}_{2}$ Reduction in Enzymatic Biofuel Cells, Chem. Rev., 118 (2018) 2392-2468

[17] S. Cosnier, A.J. Gross, F. Giroud, M. Holzinger, Beyond the hype surrounding biofuel cells: What's the future of enzymatic fuel cells?, Curr. Opin. Electrochem., 12 (2018) 148-155. [18] F. Conzuelo, A. Ruff, W. Schuhmann, Self-powered bioelectrochemical devices, Curr. Opin. Electrochem., 12 (2018) 156-163.

[19] S. Ferri, K. Kojima, K. Sode, Review of Glucose Oxidases and Glucose Dehydrogenases: A Bird's eye view of glucose sensing enzymes, J. Diabetes. Sci. Technol., 5 (2011) 1068-1076. [20] R. Wilson, A.P.F. Turner, Glucose oxidase: An ideal enzyme, Biosens. Bioelectron., 7 (1992) 165-185. 
[21] S. Vogt, M. Schneider, H. Schäfer-Eberwein, G. Nöll, Determination of the pH Dependent Redox Potential of Glucose Oxidase by Spectroelectrochemistry, Anal. Chem., 86 (2014) 75307535.

[22] G.S. Wilson, Native glucose oxidase does not undergo direct electron transfer, Biosens. Bioelectron., 82 (2016) vii-viii.

[23] P.N. Bartlett, F.A. Al-Lolage, There is no evidence to support literature claims of direct electron transfer (DET) for native glucose oxidase (GOx) at carbon nanotubes or graphene, J. Electroanal. Chem., 819 (2018) 26-37.

[24] P. Radivoje, O. Raluca, S. Andreea, S. Ulrich, Ultrahigh Throughput Screening System for Directed Glucose Oxidase Evolution in Yeast Cells, Comb. Chem. High Throughput Screen., 14 (2011) 55-60.

[25] R. Ostafe, R. Prodanovic, J. Nazor, R. Fischer, Ultra-High-Throughput Screening Method for the Directed Evolution of Glucose Oxidase, Chem. Biol., 21 (2014) 414-421.

[26] D. Petrović, D. Frank, S.C.L. Kamerlin, K. Hoffmann, B. Strodel, Shuffling Active Site Substate Populations Affects Catalytic Activity: The Case of Glucose Oxidase, ACS Catalysis, 7 (2017) 6188-6197.

[27] X. Ning, Y. Zhang, T. Yuan, Q. Li, J. Tian, W. Guan, B. Liu, W. Zhang, X. Xu, Y. Zhang, Enhanced Thermostability of Glucose Oxidase through Computer-Aided Molecular Design, Int. J. Mol. Sc., 19 (2018) 425-436.

[28] G. Kovačević, R. Ostafe, A.M. Balaž, R. Fischer, R. Prodanović, Development of GFPbased high-throughput screening system for directed evolution of glucose oxidase, J. Biosc. Bioeng., 127 (2018) 30-37.

[29] T. Tu, Y. Wang, H. Huang, Y. Wang, X. Jiang, Z. Wang, B. Yao, H. Luo, Improving the thermostability and catalytic efficiency of glucose oxidase from Aspergillus niger by molecular evolution, Food Chem., 281 (2019) 163-170. 
[30] J. Marín-Navarro, N. Roupain, D. Talens-Perales, J. Polaina, Identification and Structural Analysis of Amino Acid Substitutions that Increase the Stability and Activity of Aspergillus niger Glucose Oxidase, PloS one, 10 (2015) e0144289-e0144289.

[31] D. Muller, Oxidation von glukose mit extratkten aus Aspergillus niger, Biochem. Z., 199 (1928) 136-170.

[32] W. Franke, M. Deffner, Zur Kenntnis der sog. Glucose-oxydase. II, Just. Lieb. Annal. Chem., 541 (1939) 117-150.

[33] W. Franke, Zur Kenntnis der sog. Glucose-oxydase. III, Just. Lieb. Annal. Chem., 555 (1944) 111-132.

[34] C.E. Coulthard, R. Michaelis, W.F. Short, G. Sykes, G.E.H. Skrimshire, A.F.B. Standfast, J.H. Birkinshaw, H. Raistrick, Notatin: an Anti-bacterial Glucose-aerodehydrogenase from Penicillium notatum Westling, Nature, 150 (1942) 634.

[35] C.E. Coulthard, R. Michaelis, W.F. Short, G. Sykes, Notatin: an anti-bacterial glucoseaerodehydrogenase from Penicillium notatum Westling and Penicillium resticulosum sp. nov, Biochem. J., 39 (1945) 24-36.

[36] A. Fleming, On the Antibacterial Action of Cultures of a Penicillium, with Special Reference to their Use in the Isolation of B. influenza, Br. J. Exp. Path., 10 (1929) 226-236.

[37] E.C. Roberts, C.K. Cain, R.D. Muir, F.J. Reithel, W.L. Gaby, J.T. Van Bruggen, D.M. Homan, P.A. Katzman, L.R. Jones, E.A. Doisy, Penicillin B: an antibacterial substance from Penicillium notatum, J. Biol. Chem., 147 (1943) 47-58.

[38] J.T. Van Bruggen, F.J. Reithel, C.K. Cain, P.A. Katzman, E.A. Doisy, R.D. Muir, E.C. Roberts, W.L. Gaby, D.M. Homan, L.R. Jones, Penicillin B : Preparation, Purification, and Mode of Action, J. Biol. Chem., 148 (1943) 365-378.

[39] W. Kocholaty, Cultural Characteristics of Penicillium Notatum in Relation to the Production of Antibacterial Substance, J. Bacteriol., 44 (1942) 469. 
[40] W. Kocholaty, Purification and properties of the second antibacterial substance produced by Penicillium notatum, Science, 97 (1943) 186-187.

[41] J.H. Birkinshaw, H. Raistrick, Notatin: an Antibacterial Glucose Aero-dehydrogenase from Penicillium notatum Westling, J. Biol. Chem., 148 (1943) 459-460.

[42] D. Keilin, E.F. Hartree, Prosthetic Group of Glucose Oxidase (Notatin), Nature, 157 (1946) 801.

[43] D. Keilin, E.F. Hartree, Properties of glucose oxidase (notatin), Biochem. J., 42 (1948) 221.

[44] D. Keilin, E.F. Hartree, Specificity of glucose oxidase (notatin), Biochem. J., 50 (1952) $331-341$

[45] H. Eichenseer, M.C. Mathews, J.L. Bi, J.B. Murphy, G.W. Felton, Salivary glucose oxidase: Multifunctional roles for Helicoverpa zea, Arch. Ins. Biochem. Physiol., 42 (1999) 99109.

[46] K. Ohashi, S. Natori, T. Kubo, Expression of amylase and glucose oxidase in the hypopharyngeal gland with an age-dependent role change of the worker honeybee (Apismellifera L.), Eur. J. Biochem., 265 (1999) 127-133.

[47] K. Afshar, P.J. Dufresne, L. Pan, M. Merkx-Jacques, J.C. Bede, Diet-specific salivary gene expression and glucose oxidase activity in Spodoptera exigua (Lepidoptera: Noctuidae) larvae, J. Ins. Physiol., 56 (2010) 1798-1806.

[48] R.C. Bean, W.Z. Hassid, Carbohydrate oxidase from a red alga, Iridophycus flaccidum, J. Biol. Chem., 218 (1956) 425-436.

[49] R.C. Bean, G.G. Porter, B.M. Steinberg, Carbohydrate Metabolism of Citrus Fruits: II. Oxidation of sugars by an anerohydrogenase from young orange fruits, J. Biol. Chem., 236 (1961) 1235-1240.

[50] V. Munk, J. Pásková, J. Hanus, Glucose oxidase of Aspergillus niger, Folia Microbiol., 8 (1963) 203-214. 
[51] B.E. Swoboda, V. Massey, Purification and Properties of the Glucose Oxidase from Aspergillus Niger, J .Biol. Chem., 240 (1965) 2209-2215.

[52] K.R. Frederick, J. Tung, R.S. Emerick, F.R. Masiarz, S.H. Chamberlain, A. Vasavada, S. Rosenberg, S. Chakraborty, L.M. Schopter, V. Massey, Glucose oxidase from Aspergillus niger. Cloning, gene sequence, secretion from Saccharomyces cerevisiae and kinetic analysis of a yeast-derived enzyme, J. Biol. Chem., 265 (1990) 3793-3802.

[53] H.J. Hecht, H.M. Kalisz, J. Hendle, R.D. Schmid, D. Schomburg, Crystal structure of glucose oxidase from Aspergillus niger refined at 2.3 Ã reslution, J. Mol. Biol., 229 (1993) $153-172$

[54] M. Kriaa, R. Kammoun, Producing Aspergillus tubingensis CTM507 Glucose oxidase by Solid state fermentation versus submerged fermentation: process optimization and enzyme stability by an intermediary metabolite in relation with diauxic growth, J. Chem. Technol. Biotechnol., 91 (2016) 1540-1550.

[55] Shweta V. Bhat, B.R. Swathi, M. Rosy, M. Govindappa, Isolation and charecterization of Glucose Oxidase (GOD) from Aspergillus flavus and Penicillium sp., Int. J. Curr. Microbiol. App. Sci 2(2013) 153-161.

[56] A.A. N.G, D. Arbain, M.S. Ahmad, Effects of Selected Medium Components for Production of Glucose Oxidase by a Local Isolate Aspergillus Terreus UniMAP AA-1, APCBEE Procedia, 2 (2012) 125-128.

[57] C. Simpson, J. Jordaan, N.S. Gardiner, C. Whiteley, Isolation, purification and characterization of a novel glucose oxidase from Penicillium sp. CBS 120262 optimally active at neutral pH, Prot. Exp. Purif., 51 (2007) 260-266.

[58] D. Rando, G.W. Kohring, F. Giffhorn, Production, purification and characterization of glucose oxidase from a newly isolated strain of Penicillium pinophilum, Appl. Microbiol. Biotechnol., 48 (1997) 34-40. 
[59] K. Kusai, I. Sekuzu, B. Hagihara, K. Okunuki, S. Yamauchi, M. Nakai, Crystallization of glucose oxidase from Penicillium amagasakiense, Biochim. Biophys. Acta, 40 (1960) 555-557. [60] H.M. Kalisz, J. Hendle, R.D. Schmid, Purification of the glycoprotein glucose oxidase from Penicillium amagasakiense by high-performance liquid chromatography, J. Chromat., 521 (1990) 245-250.

[61] H.M. Kalisz, K. Schmidt, Structural and biochemical properties of glycosylated and deglycosylated glucose oxidase from Penicilium amagasakiense, Appl. Microbiol. Biotechnol., 47 (1997) 502-507.

[62] M. Kiess, H.J. Hecht, H.M. Kalisz, Glucose oxidase from Penicillium amagasakiense. Primary structure and comparison with other glucose-methanol-choline (GMC) oxidoreductases, Eur. J. Biochem., 252 (1998) 90-99.

[63] O. Courjean, N. Mano, Recombinant glucose oxidase from Penicillium amagasakiense for efficient bioelectrochemical applications in physiological conditions, J. Biotechnol., 151 (2011) $122-129$.

[64] K.-o. Eriksson, I. Kourteva, K. Yao, J.-1. Liao, F. Kilár, S. Hjertén, G. Chaga, Application of high-performance chromatographic and electrophoretic methods to the purification and characterization of glucose oxidase and catalase from penicillium chrysogenum, J. Chrom. A, 397 (1987) 239-249.

[65] É. Leiter, F. Marx, T. Pusztahelyi, H. Haas, I. Pócsi, Penicillium chrysogenum glucose oxidase - a study on its antifungal effects, J. Appl. MicrobioL., 97 (2004) 1201-1209.

[66] H. Gorniak, J. Kaczkowski, Isolation and characterization of glcuose oxidase from mycelium and nutrient of Penicillium notatum cultures, Biochem. J., 22 (1974) 351-355.

[67] N.H. Bhatti, N. Saleem, Characterization of glucose oxidase from Penicillium notatum, Food Technol. Biotechnol., 47 (2009) 331-335.

[68] H.-W. Kim, S. Kimura, N. Ohno, M. Okadome, H. Takahashi, S. Amachi, H. Shinoyama, T. Fujii, Purification of Glucose Oxidase and Catalase Produced by the Apple Blue Mold, 
Penicillium expansum O-385-10, and Their Characteristics Including the Browning of Apple Fruit, Jap. J. Food Microbiol., 22 (2005) 10-16.

[69] S. Manivannan, K. Kathiresan, Effect of Medium Composition on Glucose Oxidase Production by Penicillium fellutanum Isolated from Mangrove Rhizosphere Soil, Res. J. Microbiol., 2 (2007) 294-298.

[70] T.V. Semashko, R.V. Mikhailova, A.N. Eremin, Extracellular Glucose Oxidase of Penicillium funiculosum 46.1, Appl. Biochem. Microbiol., 39 (2003) 368-374.

[71] A.N. Eryomin, A.P. Drozhdenyuk, G.K. Zhavnerko, T.V. Semashko, R.V. Mikhailova, Quartz Sand as an Adsorbent for Purification of Extracellular Glucose Oxidase from Penicillium funiculosum 46.1, Appl. Biochem. Microbiol., 40 (2004) 151-157.

[72] M.V. Sukhacheva, M.E. Davydova, A.I. Netrusov, Production of Penicillium funiculosum 433 glucose oxidase and its properties, Appl. Biochem. Microbiol., 40 (2004) 25-29.

[73] A.N. Eryomin, M.V. Makarenko, L.A. Zhukovskaya, R.V. Mikhailova, Isolation and characterization of extracellular glucose oxidase from Penicillium adametzii LF F-2044.1, Appl. Biochem. Microbiol., 42 (2006) 304-311.

[74] J.J. Kulys, N.K. Čénas, Oxidation of glucose oxidase from Penicillium vitale by one- and two-electron acceptors, Biochim. Biophys. Acta 744 (1983) 57-63.

[75] A.M.V. Garzillo, S. Di Paolo, M. Fenice, M. Petruccioli, V. Buonocore, F. Federici, Production, purification and characterization of glucose oxidase from Penicillium variabile P16, Biotech. Appl. Biochem., 22 (1995) 169-178.

[76] M. Petruccioli, P. Piccioni, F. Federici, Glucose oxidase overproduction by the mutant strain M-80.10 of Penicillium variabile in a benchtop fermenter, Enz. Microb. Tech., 21 (1997) $458-462$.

[77] V. Pulci, R. D'Ovidio, M. Petruccioli, F. Federici, The glucose oxidase of Penicillium variabile P16: gene cloning, sequencing and expression, Lett. Appl. Microbiol., 38 (2004) 233238. 
[78] S. Crognale, V. Pulci, V. Brozzoli, M. Petruccioli, F. Federici, Expression of Penicillium variabile P16 glucose oxidase gene in Pichia pastoris and characterization of the recombinant enzyme, Enz. Microb. Tech., 39 (2006) 1230-1235.

[79] K.-A. Caridis, P. Christakopoulos, B.J. Macris, Simultaneous production of glucose oxidase and catalase by Alternaria alternata, Appl. Microbiol. Biotechnol., 34 (1991) 794-797. [80] S. Liu, S. Oeljeklaus, B. Gerhardt, B. Tudzynski, Purification and characterization of glucose oxidase of Botrytis cinerea, Physiol. Mol. Plant Path., 53 (1998) 123-132.

[81] K. Ramasamy, R.L. Kelley, C.A. Reddy, Lack of lignin degradation by glucose oxidasenegative mutants of Phanerochaete chrysosporium, Biochem. Biophy. Res. Comm., 131 (1985) 436-441.

[82] R.L. Kelley, C.A. Reddy, Purification and characterization of glucose oxidase from ligninolytic cultures of Phanerochaete chrysosporium, J. Bacteriol., 166 (1986) 269-274.

[83] K.-S. Shin, H.-D. Youn, Y.-H. Han, S.-O. Kang, Y.C. Hah, Purification and characterisation of d-glucose oxidase from white-rot fungus Pleurotus ostreatus, Eur. J. Biochem., 215 (1993) 747-752.

[84] K.K.-A. Kim, D.R. Fravel, G.C. Papavizas, Glucose oxidase as the antifungal principle of talaron from Talaromyces flavus, Can. J. Microbiol., 36 (1990) 760-764.

[85] M. Hodgkins, P. Sudbery, D. Mead, D.J. Ballance, A. Goodey, Expression of the glucose oxidase gene from Aspergillus niger in Hansenula polymorpha and its use as a reporter gene to isolate regulatory mutations, Yeast, 9 (1993) 625-635.

[86] H. Whittington, S. Kerry-Williams, K. Bidgood, N. Dodsworth, J. Peberdy, M. Dobson, E. Hinchliffe, D.J. Ballance, Expression of the Aspergillus niger glucose oxidase gene in A. niger, A. nidulans and Saccharomyces cerevisiae, Curr. Gen., 18 (1990) 531-536.

[87] A. De Baetselier, P. Dohet, M. De Beukelaer, V. Ha-Thi, J. Hanotier, K. Frederick, S. Rosenberg, A. Vasavada, A new production method for glucose oxidase, J. Biotechnol., 24 (1992) 141-148. 
[88] E.H. Park, Y.M. Shin, Y.Y. Lim, T.H. Kwon, D.H. Kim, M.S. Yang, Expression of glucose oxidase by using recombinant yeast, J. Biotechnol., 81 (2000) 35-44.

[89] D.F. Malherbe, M. du Toit, R.R. Cordero Otero, P. van Rensburg, I.S. Pretorius, Expression of the Aspergillus niger glucose oxidase gene in Saccharomyces cerevisiae and its potential applications in wine production, Appl. Microbiol. Biotech., 61 (2003) 502-511.

[90] Z. Zhu, C. Momeu, M. Zakhartsev, U. Schwaneberg, Making glucose oxidase fit for biofuel cell applications by directed protein evolution, Biosens. Bioelectron., 21 (2006) 20462051

[91] E.P. Kopetzki, DE), , K.H. Lehnert, DE), Hypoglycosylated recombinant glucose oxidases, Boehringer Mannheim GmbH (Mannheim, DE), United States, 1997.

[92] L. Lehle, A. Eiden, K. Lehnert, A. Haselbeck, E. Kopetzki, Glycoprotein biosynthesis in Saccharomyces cerevisiae: $n g d 29$, an N-glycosylation mutant allelic to och1 having a defect in the initiation of outer chain formation, FEBS Lett., 370 (1995) 41-45.

[93] Y.F. Zhou, X.E. Zhang, H. Liu, C.G. Zhang, A.E. Cass, Cloning and expression of Aspergillus niger glucose oxidase gene in methylotrophic yeast, Chin. J. biotechnol., 17 (2001) 400-405.

[94] L.Q. Chen, X.E. Zhang, W.H. Xie, Y.F. Zhou, Z.P. Zhang, A.E.G. Cass, Genetic modification of glucose oxidase for improving performance of an amperometric glucose biosensor, Biosens. Bioelectron., 17 (2002) 851-857.

[95] M. Yamaguchi, Y. Tahara, A. Nakano, T. Taniyama, Secretory and continuous expression of Aspergillus niger glucose oxidase gene in Pichia pastoris, Prot. Exp. Purif., 55 (2007) 273278.

[96] Y. Guo, F. Lu, H. Zhao, Y. Tang, Z. Lu, Cloning and Heterologous Expression of Glucose Oxidase Gene from Aspergillus niger Z-25 in Pichia pastoris, Appl. Biochem. Biotech., (2009) $1-12$. 
[97] G. Kovačević, M. Blažić, B. Draganić, R. Ostafe, M. Gavrović-Jankulović, R. Fischer, R. Prodanović, Cloning, Heterologous Expression, Purification and Characterization of M12 Mutant of Aspergillus niger Glucose Oxidase in Yeast Pichia pastoris KM71H, Mol. Biotech., 56 (2014) 305-311.

[98] Y. Meng, M. Zhao, M. Yang, Q. Zhang, J. Hao, Y. Meng, Production and characterization of recombinant glucose oxidase from Aspergillus niger expressed in Pichia pastoris, Lett. Appl. Microbiol., 58 (2014) 393-400.

[99] F. Belyad, A.A. Karkhanei, J. Raheb, Expression, characterization and one step purification of heterologous glucose oxidase gene from Aspergillus niger ATCC 9029 in Pichia pastoris, EuPA Open Proteomics, 19 (2018) 1-5.

[100] M. Kriechbaum, H.J. Heilmann, F.J. Wientjes, M. Hahn, K.-D. Jany, H.G. Gassen, F. Sharif, G. Alaeddinoglu, Cloning and DNA sequence analysis of the glucose oxidase gene from Aspergillus niger NRRL-3, FEBS Lett., 255 (1989) 63-66.

[101] D.G. Hatzinikolaou, O.C. Hansen, B.J. Macris, A. Tingey, D. Kekos, P. Goodenough, P. Stougaard, A new glucose oxidase from Aspergillus niger: characterization and regulation studies of enzyme and gene, Appl. Microbiol. Biotechnol., 46 (1996) 371-381.

[102] S. Witt, M. Singh, H.M. Kalisz, Structural and kinetic properties of nonglycosylated recombinant Penicillium amagasakiense glucose oxidase expressed in Escherichia coli, Appl. Environ. Microbiol., 64 (1998) 1405-1411.

[103] O. Courjean, V. Flexer, A. Prevoteau, E. Suraniti, N. Mano, Effect of degree of glycosylation on charge of glucose oxidase and redox hydrogel catalytic efficiency, ChemPhysChem, 11 (2010) 2795-2797.

[104] E. Suraniti, O. Courjean, S. Gounel, E. Tremey, N. Mano, Uncovering and Redesigning a key amino acid of Glucose Oxidase for Improved Biotechnological Applications, Electroanalysis, 25 (2013) 606-611. 
[105] D.G. Hatzinikolaou, B.J. Macris, Factors regulating production of glucose oxidase by Aspergillus niger, Enz. Microb.Technol., 17 (1995) 530-534.

[106] D.R. Cavener, GMC oxidoreductases: A newly defined family of homologous proteins with diverse catalytic activities, J. Mol. Biol., 223 (1992) 811-814.

[107] M.W. Fraaije, A. Mattevi, Flavoenzymes: diverse catalysts with recurrent features, Tr. Biochem. Sci., 25 (2000) 126-132.

[108] W. Dijkman, G. Gonzalo, A. Mattevi, M. Fraaije, Flavoprotein oxidases: Classification and applications, Appl. Microbiol. Biotechnol., 97 (2013) 5177-5188.

[109] G. Wohlfahrt, S. Witt, J. Hendle, D. Schomburg, H.M. Kalisz, H.J. Hecht, 1.8 and 1.9 Â... resolution structures of the Penicillium amagasakiense and Aspergillus niger glucose oxidases as a basis for modelling substrate complexes, Acta Crystal. Section D: Biol. Crystal., 55 (1999) 969-977.

[110] P.-R. Kommoju, Z.-w. Chen, R.C. Bruckner, F.S. Mathews, M.S. Jorns, Probing Oxygen Activation Sites in Two Flavoprotein Oxidases Using Chloride as an Oxygen Surrogate, Biochem. J., 50 (2011) 5521-5534.

[111] S. Nakamura, S. Fujiki, Comparative studies on the glucose oxidases of Aspergillus niger and penicillium amagasakiense, J. Biochem., 63 (1968) 51-58.

[112] O. Courjean, F. Gao, N. Mano, Deglycosylation of glucose oxidase for direct and efficient glucose electrooxidation on a glassy carbon electrode, Angew. Chem. Int. Ed., 48 (2009) 5897 5899.

[113] H.M. Kalisz, H.J. Hecht, D. Schomburg, R.D. Schmid, Effects of carbohydrate depletion on the structure, stability and activity of glucose oxidase from Aspergillus niger, Biochim. Biophys. Acta, 1080 (1991) 138-142.

[114] K. Takegawa, K. Fujiwara, S. Iwahara, K. Yamamoto, T. Tochikura, Effect of deglycosylation of N-linked sugar chains on glucose oxidase from Aspergillus niger, Biochem. Cell Biol., 67 (1989) 460-464. 
[115] H.M. Kalisz, H.-J. Hecht, D. Schomburg, R.D. Schmid, Crystallization and preliminary X-ray diffraction studies of a deglycosylated glucose oxidase from Aspergillus niger, J. Mol. Biol., 213 (1990) 207-209.

[116] E.C. Adams, R.L. Mast, A.H. Free, Specificity of glucose oxidase, Arch. Biochem. Biophys., 91 (1960) 230-234.

[117] J.H. Pazur, K. Kleppe, The Oxidation of Glucose and Related Compounds by Glucose Oxidase from Aspergillus niger, Biochemistry, 3 (1964) 578-583.

[118] T. Jithendar, K. Sairam, V. Verma, Research journal of pharmaceutical, biological and chemical sciences purification, characterization, thermostability and shelf life studies of glucose oxidase from Aspergillus niger PIL7, Res. J. Pharm. Biol. Chem. Sci. , 6 (2015) 16661678.

[119] K. Kleppe, The Effect of Hydrogen Peroxide on Glucose Oxidase from Aspergillus niger, Biochemistry, 5 (1966) 139-143.

[120] J. Bao, K. Furumoto, M. Yoshimoto, K. Fukunaga, K. Nakao, Competitive inhibition by hydrogen peroxide produced in glucose oxidation catalyzed by glucose oxidase, Biochem. Eng. J., 13 (2003) 69-72.

[121] M.J. Rogers, K.G. Brandt, Interaction of halides ions with aspergillus niger Glucose oxidase, Biochemistry, 10 (1971) 4630-4635.

[122] L. Tongbu, P. Xinyu, Y. Huiying, J. Liangnian, The production of glucose oxidase using the waste myceliums of Aspergillus niger and the effects of metal ions on the activity of glucose oxidase, Enz. Microb.Technol., 19 (1996) 339-342.

[123] A. Ahmad, M.S. Akhtar, V. Bhakuni, Monovalent cation-Induced conformational chnage in glucose oxidase leading to a stabilization of the enzyme, Biochemistry, (2001) 1945-1955. [124] M.S. Akhtar, A. Ahmad, V. Bhakani, Divalent cation induced changes in structural propertie sof the dimeric enzyme glucose oxidase: duel effect of dimer stabilization and 
dissociaion with loss of cooperative interactions in enzyme monomer, Biochemistry, 41 (2002) 7142-7149.

[125] M. Meyer, G. Wohlfahrt, J. Knäblein, D. Schomburg, Aspects of the mechanism of catalysis of glucose oxidase: A docking, molecular mechanics and quantum chemical study, J. Comput.-Aided Mol. Des., 12 (1998) 425-440.

[126] S. Witt, G. Wohlfahrt, D. Schomburg, H.J. Hecht, H.M. Kalisz, Conserved arginine-516 of Penicillium amagasakiense glucose oxidase is essential for the efficient binding of glucose, Biochem. J., 347 (2000) 553-559.

[127] M. Alvarez-Icaza, H.M. Kalisz, H.J. Hecht, K.D. Aumann, D. Schomburg, R.D. Schmid, The design of enzyme sensors based on the enzyme structure, Biosens. Bioelectron., 10 (1995) $735-742$

[128] S. Demim, E.A.H. Hall, Breaking the barrier to fast electron transfer, Bioelectrochemistry, 76 (2009) 19-27.

[129] I.H. Segel, Enzyme Kinetics: Behavior and Analysis of Rapid Equilibrium and SteadyState Enzyme Systems John Wiley \& Sons, New York, 1993.

[130] Q.H. Gibson, B.E.P. Swoboda, V. Massey, Kinetics and mechanism of action of glucose oxidase, J. Biol. Chem., 239 (1964) 3927-3934.

[131] B.E.P. Swoboda, V. Massey, The relationship between molecular conformation and the binding of flavin adenine dinucleotide in glucose oxidase, J. Biol. Chem, 240 (1965) 22092215.

[132] H.J. Bright, M. Appleby, The pH Dependence of the Individual Steps in the Glucose Oxidase Reaction, J. Biol. Chem., 244 (1969) 3625-3634.

[133] M.K. Weibel, H.J. Bright, The glucose oxidase mechanism. Interpretation of the $\mathrm{pH}$ dependence, J. Biol. Chem., 246 (1971) 2734-2744. 
[134] M.T. Stankovich, L.M. Schopfer, V. Massey, Determination of glucose oxidase oxidation-reduction potentials and the oxygen reactivity of fully reduced and semiquinoid forms, J. Biol. Chem., 253 (1978) 4971-4979.

[135] G. Wohlfahrt, S. Trivić, J. Zeremski, D. Peričin, V. Leskovac, The chemical mechanism of action of glucose oxidase from Aspergillus niger, Mol. Cell. Biochem., 260 (2004) 69-83.

[136] V. Leskovac, S. Trivic, G. Wohlfarht, J. Kandrac, D. Pericin, Glucose Oxidase from Aspergillus Niger: The mechanism of action with molecular oxygen, quinones, and oneelectron acceptors, Int. J. Biochem. Cell Biol., 37 (2005) 731-750.

[137] A. Mattevi, To be or not to be an oxidase: challenging the oxygen reactivity of flavoenzymes, Tr. Biochem. Sci., 31 (2006) 276-283.

[138] Q. Su, J.P. Klinman, Nature of oxygen activation in glucose oxidase from Aspergillus niger: The importance of electrostatic stabilization in superoxide formation, Biochemistry, 38 (1999) 8572-8581.

[139] J.P. Klinman, Life as aerobes: are there simple rules for activation of dioxygen by enzymes?, J. Biol. Inorg. Chem., 6 (2001) 1-13.

[140] J.P. Roth, J.P. Klinman, Catalysis of electron transfer during activation of $\mathrm{O}_{2}$ by the flavoprotein glucose oxidase, Proc. Natl. Acad. Sci. U S A, 100 (2003) 62-67.

[141] J.P. Roth, R. Wincek, G. Nodet, D.E. Edmondson, W.S. McIntire, J.P. Klinman, Oxygen isotope effects on electron transfer to $\mathrm{O}_{2}$ probed using chemically modified flavins bound to glucose oxidase, J. Am. Chem. Soc., 126 (2004) 15120-15131.

[142] J.P. Klinman, How do enzymes activates oxygen without inactivating themselves, Acc. Chem. Res. , 40 (2007) 325-333.

[143] V. Massey, Activation of molecular oxygen by flavins and flavoproteins, J. Biol. Chem., 269 (1994) 22459-22462.

[144] R. Prabhakar, P.E.M. Siegbahn, B.F. Minaev, A theoretical study of dioxygen activation by glucose oxidase and coper amine oxidase, Biochim. Biophys. Acta., 1647 (2003) 173-178. 
[145] G. Gadda, Oxygen Activation in Flavoprotein Oxidases: The Importance of Being Positive, Biochemistry, 51 (2012) 2662-2669.

[146] L. Deng, C. Hu, X. Qin, L. Li, Y. Zhang, P. Li, X. Chen, The remote arginine promoting the dehydrogenation of glucose in glucose oxidase via a proton-coupled double-electron transfer mechanism, J. Catal., 367 (2018) 150-158.

[147] L. Piubelli, M. Pedotti, G. Molla, S. Feindler-Boeckh, S. Ghisla, M.S. Pilone, L. Pollegioni, On the oxygen reactivity of flavoprotein oxidases: an oxygen access tunnel and gate in brevibacterium sterolicum cholesterol oxidase, J. Biol. Chem., 283 (2008) 24738-24747.

[148] N.G.H. Leferink, M.W. Fraaije, H.-J. Joosten, P.J. Schaap, A. Mattevi, W.J.H. van Berkel, Identification of a Gatekeeper Residue That Prevents Dehydrogenases from Acting as Oxidases, J. Biol. Chem., 284 (2009) 4392-4397.

[149] R. Baron, C. Riley, P. Chenprakhon, K. Thotsaporn, R.T. Winter, A. Alfieri, F. Forneris, W.J.H. van Berkel, P. Chaiyen, M.W. Fraaije, A. Mattevi, J.A. McCammon, Multiple pathways guide oxygen diffusion into flavoenzyme active sites, PNAS, 106 (2009) 10603-10608.

[150] A. Kohen, T. Jonsson, J.P. Klinman, Effects of protein glycosylation on catalysis: changes in hydrogen tunneling and enthalpy of activation in the glucose oxidase reaction, Biochemistry, 36 (1997) 2603-2611.

[151] S.L. Seymour, J.P. Klinman, Comparison of rates and kinetic isotope effects using PEGmodified variants and glycoforms of glucose oxidase: the relationship of modification of the protein envelope to C-H activation and tunneling, Biochemistry, 41 (2002) 8747-8758.

[152] T.S. Wong, U. Schwaneberg, Protein engineering in bioelectrocatalysis, Curr. Opin. Biotechnol., 14 (2003) 590-596.

[153] G. Güven, R. Prodanovic, U. Schwaneberg, Protein Engineering - An Option for Enzymatic Biofuel Cell Design, Electroanalysis, 22 (2010) 765-775.

[154] D.J. Caruana, S. Howorka, Biosensors and biofuel cells with engineered proteins, Mol. BioSyst., 6 (2010) 1-9. 
[155] N. Mano, A 280 microW $\mathrm{cm}^{-2}$ biofuel cell operating at low glucose concentration, Chem Commun (Camb), (2008) 2221-2223.

[156] R.A. Marcus, On the theory of oxidation-reduction reactions involving electron transfer, J. Chem. Phys., 24 (1956) 966-978.

[157] R.A. Marcus, N. Sutin, Electron transfers in chemistry and biology, Biochim. Biophys. Acta, 811 (1985) 265-322.

[158] H.C. Bong, S.L. Chang, J.P. Hye, M.L. Jeong, A glucose sensor comprising glucose oxidase variant in: K.R.I.O.B.A. Biotechnology (Ed.)Korea, 2009.

[159] M. Kizling, M. Dzwonek, A. Wieckowska, R. Bilewicz, Gold nanoparticles in bioelectrocatalysis - The role of nanoparticle size, Curr. Opin. Electrochem., 12 (2018) 113120.

[160] D. Pankratov, R. Sundberg, D.B. Suyatin, J. Sotres, A. Barrantes, T. Ruzgas, I. Maximov, L. Montelius, S. Shleev, The influence of nanoparticles on enzymatic bioelectrocatalysis, RSC Adv., 4 (2014) 38164-38168.

[161] N. German, A. Kausaite-Minkstimiene, A. Ramanavicius, T. Semashko, R. Mikhailova, A. Ramanaviciene, The use of different glucose oxidases for the development of an amperometric reagentless glucose biosensor based on gold nanoparticles covered by polypyrrole, Electrochim. Acta, 169 (2015) 326-333.

[162] A. Trifonov, A. Stemmer, R. Tel-Vered, Enzymatic self-wiring in nanopores and its application in direct electron transfer biofuel cells, Nanoscale Adv., 1 (2019) 347-356.

[163] E. Malel, D. Mandler, Direct Electron Transfer between Glucose Oxidase and Gold Nanoparticles; When Size Matters, ChemElectroChem, 6 (2019) 147-154.

[164] A. Ramanavicius, N. German, A. Ramanaviciene, Evaluation of Electron Transfer in Electrochemical System Based on Immobilized Gold Nanoparticles and Glucose Oxidase, J. Electrochem. Soc., 164 (2017) G45-G49. 
[165] A. Riklin, E. Katz, I. Wiliner, A. Stocker, A.F. Bückmann, Improving enzyme-electrode contacts by redox modification of cofactors, Nature, 376 (1995) 672-675.

[166] I. Willner, V. Heleg-Shabtai, R. Blonder, E. Katz, G. Tao, A.F. Bückmann, A. Heller, Electrical Wiring of Glucose Oxidase by Reconstitution of FAD-Modified Monolayers Assembled onto Au-Electrodes, J. Am. Chem. Soc., 118 (1996) 10321-10322.

[167] M. Zayats, E. Katz, I. Willner, Electrical Contacting of Glucose Oxidase by SurfaceReconstitution of the Apo-Protein on a Relay-Boronic Acid-FAD Cofactor Monolayer, J. Am. Chem. Soc., 124 (2002) 2120-2121.

[168] O.A. Raitman, E. Katz, A.F. Bückmann, I. Willner, Integration of Polyaniline/Poly(acrylic acid) Films and Redox Enzymes on Electrode Supports: An in Situ Electrochemical/Surface Plasmon Resonance Study of the Bioelectrocatalyzed Oxidation of Glucose or Lactate in the Integrated Bioelectrocatalytic Systems, J. Am. Chem. Soc., 124 (2002) 6487-6496.

[169] I. Willner, R. Baron, B. Willner, Integrated nanoparticle-biomolecule systems for biosensing and bioelectronics, Biosens. Bioelectron., 22 (2007) 1841-1852.

[170] Y. Xiao, F. Patolsky, E. Katz, J.F. Hainfield, I. Willner, "Plugging into Enzymes " : Nanowiring of redox enzymes by a gold particles, Science, 299 (2003) 1877-1881.

[171] J.T. Holland, C. Lau, S. Brozik, P. Atanassov, S. Banta, Engineering of Glucose Oxidase for Direct Electron Transfer via Site-Specific Gold Nanoparticle Conjugation, J. Am. Chem. Soc., 133 (2012) 19262-19265.

[172] J.T. Holland, J.C. Harper, P.L. Dolan, M.M. Manginell, D.C. Arango, J.A. Rawlings, C.A. Apblett, S.M. Brozik, Rational Redesign of Glucose Oxidase for Improved Catalytic Function and Stability, PLOS ONE, 7 (2012) e37924.

[173] H.M. Kalisz, W. Kunnecke, Elektrode mit deglykosyliertem glykoprotein-enzym und deren verwendung, Germany, 1989. 
[174] D.M. Fraser, S.M. Zakeeruddin, M. Grätzel, Mediation of glycoslated and partiallydeglycosylated glucose oxidase of Aspergillus niger by a ferrocene-derivatised detergent, Biochim. Biophys. Acta., 1099 (1992) 91-101.

[175] J.H.T. Luong, J.D. Glennon, A. Gedanken, S.K. Vashist, Achievement and assessment of direct electron transfer of glucose oxidase in electrochemical biosensing using carbon nanotubes, graphene, and their nanocomposites, Microchim. Acta, 184 (2017) 369-388.

[176] A. Prévoteau, O. Courjean, N. Mano, Deglycosylation of glucose oxidase to improve biosensors and biofuel cells Electrochem. Comm., 12 (2010) 213-215.

[177] A. Heller, Electrical wiring of redox enzymes, Acc. Chem. Res., 23 (1990) 128-134.

[178] B.A. Gregg, A. Heller, Redox polymer films containing enzymes. 1. A redox-conducting epoxy cement : synthesis, characterisation, and electrocatalytic oxidation of hydroquinone, J. Phys. Chem., 95 (1991) 5970-5975.

[179] B.A. Gregg, A. Heller, Redox polymer films containing enzymes. 2. glucose oxidase containing enzymes electrodes, J. Phys. Chem., 95 (1991) 5976-5980.

[180] A. Heller, Electrical Connection of Enzyme Redox Centers to Electrodes, J Phys. Chem.B, 96 (1992) 3579-3587.

[181] A. Heller, Electron-conducting redox hydrogels: design, characteristics and synthesis, Curr. Opin. Chem. Biol., 10 (2006) 664-672.

[182] N. Mano, F. Mao, A. Heller, Electro-oxidation of glucose at an increased current density at a reducing potential, Chem Commun (Camb), (2004) 2116-2117.

[183] A. Ruff, Redox polymers in bioelectrochemistry: Common playgrounds and novel concepts, Curr. Opin. Electrochem., 5 (2017) 66-73.

[184] F. Gao, O. Courjean, N. Mano, An improved glucose $/ \mathrm{O}_{2}$ membrane-less biofuel cell through glucose oxidase purification, Biosens. Bioelectron., 25 (2009) 356-361. 
[185] E. González-Arribas, D. Pankratov, S. Gounel, N. Mano, Z. Blum, S. Shleev, Transparent and Capacitive Bioanode Based on Specifically Engineered Glucose Oxidase, Electroanalysis, 28 (2016) 1290-1297.

[186] E. Arango Gutierrez, A.-M. Wallraf, A. Balaceanu, M. Bocola, M.D. Davari, T. Meier, H. Duefel, U. Schwaneberg, How to engineer glucose oxidase for mediated electron transfer, Biotechnol. Bioeng., 115 (2018) 2405-2415.

[187] Z. Zhu, M. Wang, A. Gautman, J. Nazor, C. Momeu, R. Prodanovic, U. Schwaneberg, Directed evolution of glucose oxidase from aspergillus niger for ferrocenemethanol mediated electron transfer, Biotechnol. J., 2 (2007) 241-248.

[188] E.H. Yu, R. Prodanovic, G. Güven, R. Ostafe, U. Schwaneberg, Electrochemical Oxidation of Glucose Using Mutant Glucose Oxidase from Directed Protein Evolution for Biosensor and Biofuel Cell Applications, Appl. Biochem. Biotech., 165 (2011) 1448-1457.

[189] B.H. Ginsberg, Factors Affecting Blood Glucose Monitoring: Sources of Errors in Measurement, J. Diabet. Sc.Technol., 3 (2009) 903-913.

[190] F. Mao, N. Mano, A. Heller, Long tethers binding redox centers to polymer backbones enhance electron transport in enzyme "Wiring" hydrogels, J. Am. Chem. Soc., 125 (2003) 49514957.

[191] M. Grattieri, M. Tucci, M. Bestetti, S. Trasatti, P. Cristiani, Facilitated Electron Hopping in Nanolayer Oxygen-Insensitive Glucose Biosensor for Application in a Complex Matrix, ChemElectroChem, 3 (2016) 1884-1889.

[192] N. Mano, A. Heller, Detection of Glucose at 2 fM Concentration., Anal. Chem., 77 (2005) 729-732.

[193] N. Plumeré, Anal. Bioanal. Chem., 405 (2013) 3731-3738.

[194] N. Plumeré, J. Henig, W.H. Campbell, Enzyme-Catalyzed $\mathrm{O}_{2}$ Removal System for Electrochemical Analysis under Ambient Air: Application in an Amperometric Nitrate Biosensor, Anal. Chem., 84 (2012) 2141-2146. 
[195] F. Lopez, S. Zerria, A. Ruff, W. Schuhmann, An O 2 Tolerant Polymer/Glucose Oxidase Based Bioanode as Basis for a Self-powered Glucose Sensor, Electroanalysis, 30 (2018) 13111318.

[196] T. Ikeda, I. Katasho, M. Senda, Glucose Oxidase-Immobilized Benzoquinone-Mixed Carbon Paste Electrode with Pre-Minigrid, Anal. Sci., 1 (1985) 455-457.

[197] M.V. Pishko, A.C. Mickael, A. Heller, Amperometric Glucose Microelectrodes Prepared through Immobilization of Glucose Oxidase in Redox Hydrogels, Anal. Chem., 63 (1991) $2268-2272$

[198] C.N. Yarnitzky, Part I. Design and construction of a potentiostat for a chemical metalwalled reactor, J. Electroanal. Chem., 491 (2000) 154-159.

[199] C.N. Yarnitzky, C.N. Campbell, A.M. Caranua, G. Georgiou, A. Heller, S.M. Vreeke, Part II. Potentiodynamic on-line monitoring of the concentration of glucose in metal-walled bioreactors, J. Electroanal. Chem., 491 (2000) 160-165.

[200] O. Courjean, A. Hochedez, W. Neri, F. Louerat, E. Tremey, S. Gounel, S. Tsujimura, N. Mano, A two-step synthesis of 7,8-dichloro-riboflavin with high yield, RSC Adv., 2 (2012) 2700-2701.

[201] E. Tremey, E. Suraniti, O. Courjean, S. Gounel, C. Stines-Chaumeil, F. Louerat, N. Mano, Switching an $\mathrm{O} 2$ sensitive glucose oxidase bioelectrode into an almost insensitive by cofactor redesign, Chem. Commun., 50 (2014) 5912-5914.

[202] S. Kim, E. Nibe, S. Ferri, W. Tsugawa, K. Sode, Engineering of dye-mediated dehydrogenase property of fructosyl amino acid oxidases by site-directed mutagenesis studies of its putative proton relay system, Biotechnol. Lett., 32 (2010) 1123-1129.

[203] S. Kim, E. Nibe, W. Tsugawa, K. Kojima, S. Ferri, K. Sode, Construction of engineered fructosyl peptidyl oxidase for enzyme sensor applications under normal atmospheric conditions, Biotechnol. Lett., 34 (2012) 491-497. 
[204] P.I. Lario, N. Sampson, A. Vrielink, Sub-atomic Resolution Crystal Structure of Cholesterol Oxidase: What Atomic Resolution Crystallography Reveals about Enzyme Mechanism and the Role of the FAD Cofactor in Redox Activity, J. Mol. Biol., 326 (2003) $1635-1650$.

[205] Y. Horaguchi, S. Saito, K. Kojima, W. Tsugawa, S. Ferri, K. Sode, Construction of Mutant Glucose Oxidases with Increased Dye-Mediated Dehydrogenase Activity, Int. J. Mol. Sci., 13 (2012) 14149-14157.

[206] K.T. Kojima, JP), , K.T. Mori, JP), , S.T. Koji, JP), Glucose oxidas mutants, compositions, devices, kits and uses thereof Ultizyme International, Ltd. (Tokyo, JP), Roche Diagnostics Operations, Inc. (Indianapolis, IN, US), United States, 2014.

[207] Y. Horaguchi, S. Saito, K. Kojima, W. Tsugawa, S. Ferri, K. Sode, Engineering glucose oxidase to minimize the influence of oxygen on sensor response, Electrochim. Acta, 126 (2014) $158-161$

[208] A.M. Orville, G.T. Lountos, S. Finnegan, G. Gadda, R. Prabhakar, Crystallographic, Spectroscopic, and Computational Analysis of a Flavin C4a-Oxygen Adduct in Choline Oxidase, Biochemistry, 48 (2009) 720-728.

[209] E. Tremey, C. Stines-Chaumeil, S. Gounel, N. Mano, Designing an $\mathrm{O}_{2}$-Insensitive Glucose Oxidase for Improved Electrochemical Applications, ChemElectroChem, 4 (2017) $2520-2526$

[210] E. Arango Gutierrez, H. Mundhada, T. Meier, H. Duefel, M. Bocola, U. Schwaneberg, Reengineered glucose oxidase for amperometric glucose determination in diabetes analytics, Biosens. Bioelectron., 50 (2013) 84-90.

[211] M.A. Bocola, DE), , H.S. Duefel, DE), , E.U.A.A. Gutierrez, DE), , D.M. Heindl, DE), , T.M. Meier, DE), , H.L. Mundhada, DK), , U.K.-H. Schwaneberg, BE), , M.M. Tacke, DE), Glucose oxidase variants and methods of using the same, Roche Diabetes Care, Inc. (Indianapolis, IN, US), United States, 2018. 
[212] Y. Yamashita, I. Lee, N. Loew, K. Sode, Direct electron transfer (DET) mechanism of FAD dependent dehydrogenase complexes $\sim$ from the elucidation of intra- and inter-molecular electron transfer pathway to the construction of engineered DET enzyme complexes $\sim$, Curr. Opin. Electrochem., 12 (2018) 92-100.

[213] K. Sode, N. Loew, Y. Ohnishi, H. Tsuruta, K. Mori, K. Kojima, W. Tsugawa, J.T. LaBelle, D.C. Klonoff, Novel fungal FAD glucose dehydrogenase derived from Aspergillus niger for glucose enzyme sensor strips, Biosens. Bioelectron., 87 (2017) 305-311.

[214] H. Yoshida, G. Sakai, K. Mori, K. Kojima, S. Kamitori, K. Sode, Structural analysis of fungus-derived FAD glucose dehydrogenase, Scientific Reports, 5 (2015) 13498.

[215] K. Sode, K. Watanabe, S. Ito, K. Matsumura, T. Kikuchi, Thermostable chimeric PQQ glucose dehydrogenase, FEBS Lett, 364 (1995) 325-327.

[216] R.D. Milton, K. Lim, D.P. Hickey, S.D. Minteer, Employing FAD-dependent glucose dehydrogenase within a glucose/oxygen enzymatic fuel cell operating in human serum, Bioelectrochemistry, 106, Part A (2015) 56-63.

[217] A.J. Gross, X. Chen, F. Giroud, C. Abreu, A. Le Goff, M. Holzinger, S. Cosnier, A High Power Buckypaper Biofuel Cell: Exploiting 1,10-Phenanthroline-5,6-dione with FADDependent Dehydrogenase for Catalytically-Powerful Glucose Oxidation, ACS Catalysis, (2017) 4408-4416.

[218] T. Yamazaki, K. Kojima, K. Sode, Extended-range glucose sensor employing engineered glucose dehydrogenases, Anal. Chem., 72 (2000) 4689-4693.

[219] R. Bennett, E. Blochouse, D. Leech, Effect of individual plasma components on the performance of a glucose enzyme electrode based on redox polymer mediation of a flavin adenine dinucleotide-dependent glucose dehydrogenase, Electrochimica Acta, 302 (2019) 270276. 
[220] J.H.T. Luong, C. Masson, R.S. Brown, K.B. Male, A.L. Nguyen, Monitoring the activity of glucose oxidase during the cultivation of Aspergillus niger using novel amperometric sensor with 1, 1'-dimethylferricinium as a mediator, Biosens. Bioelectron., 9 (1994) 577-584.

[221] A. Pinczewska, M. Sosna, S. Bloodworth, J.D. Kilburn, P.N. Bartlett, High-Throughput Synthesis and Electrochemical Screening of a Library of Modified Electrodes for NADH Oxidation, J. Am. Chem. Soc., 124 (2012) 18022-18034.

[222] V. Piano, B.A. Palfey, A. Mattevi, Flavins as Covalent Catalysts: New Mechanisms Emerge, Tr. Biochem. Sci., 42 (2017) 457-469.

[223] A. Heller, Plugging metal connectors into enzymes, Nat. Biotechnol., 21 (2003) 631.

[224] P. Chaiyen, M.W. Fraaije, A. Mattevi, The enigmatic reaction of flavins with oxygen, Tr. Biochem. Sci., 37 (2012) 373-380.

[225] P. Kavanagh, D. Leech, Mediated electron transfer in glucose oxidising enzyme electrodes for application to biofuel cells: recent progress and perspectives, Phys. Chem. Chem. Phys., 15 (2013) 4859-4869.

[226] G. Cappon, G. Acciaroli, M. Vettoretti, A. Facchinetti, G. Sparacino, Wearable Continuous Glucose Monitoring Sensors: A Revolution in Diabetes Treatment, Electronics, 6 (2017) 65.

\section{Legends}

Table 1: Review related to glucose oxidase and electrochemical glucose oxidation

Table 2: Summary of the mutations realized on GOxs and their effect reported in the literature

Figure 1. Reconstructed Pymol images of GOX from A. niger (PDB: 1gal). Red: Flavin Adenine Dinucleotide; Cyan: glycosylations. These images were produced using PyMol 1.7.4.5 (Schrödinger, LLC., New York, NY, USA) 
Figure 2. Two different Pymol generated images of the FAD binding sites residues in GOx from A. niger (PDB: 1gal). These images were produced using PyMol 1.7.4.5 (Schrödinger, LLC., New York, NY, USA)

Figure 3. Diagram of the hydrogen bonds and hydrophobic interactions of the modelled substrate $\beta$-D-glucose with the active site residues in GOx from P. amagasakiense. Reprint with permission from [126]. Copyright 2000, Portland Press, LTD

Figure 4: A) Predicted electron pathway in GOx from A. niger (PDB: 1gal). In yellow: end of the first pathway at R95; in magenta, end of the second pathway at D573; in gold, the most probable pathway ending at C164. B) Comparison of the third pathway in GOx from A. niger (PDB: 1gal, red) and GOx from P. amagasakiense (PDB: 1gpe, yellow). These images were produced using PyMol 1.7.4.5 (Schrödinger, LLC., New York, NY, USA)

Figure 5: Oxidative and Reductive half Reactions during glucose oxidase catalysis. The relevant active atoms are highlighted in red. Adapted with permission from [141] and from [222]. Copyright 2004, American Chemical Society and Copyright 2017, from Elsevier

Figure 6: Proposed mechanism (A) and zoom of the key residues (B) involved in the reductive half reaction. Hydrogen bonds are indicated by yellow dashed lines. A) Reproduced with permission from[138]. Copyright 1999 American Chemical Society. B) Adapted with permission from [26]. Copyright 2017, American Chemical Society

Figure 7. Scheme of the active site residues of GOx involved in the oxidative half-reaction. Oxygen is expected to diffuse near or at the site occupied by Water110 located at $2.8 \AA$ from H516. The distance from the $\mathrm{N}$ of the His to the $\mathrm{N} 1$ position of the $\mathrm{FADH}_{2}$ is indicated by the 
dashed line. Reproduced with permission from [142]. Copyright 2007, American Chemical Society

Figure 8. Molecular model of the $\mathrm{O}_{2}^{-\bullet} /$ flavin semiquinone pair. Superoxide anion is complexed with the radical form of the coenzyme. Adapted with permission from[136]. Copyright 2005, Elsevier

Figure 9. Molecular models of the active site of GOx from A. niger with 1,2-naphtoquinone-4 -sulfonic acid (NQSA). The dotted line indicate hydrogen bonds and others possible interactions. Top Left: reduced enzyme complex with NQSA. Top right: oxidized enzyme complexed with reduced NQSA. Bottom: oxidized enzyme complex with fully reduced NQSA. Adapted with permission from[136]. Copyright 2005, Elsevier

Figure 10. A) Two routes for construction of gold nanoparticle (Au-NP)-glucose oxidase (GOx) monolayer electrodes. In the first (top left), an Au-NP with a single $N$ hydroxysuccinimide group attached is reacted with N6-( $\alpha$-aminoethyl)-flavin adenine dinucleotide to yield the FAD-functionalized Au-NP. The apo-GOx (GOx without the FAD/FADH ${ }_{2}$ cofactor) is reconstituted with the FAD-functionalized Au-NP, then assembled on the macroelectrode by reacting the NP with a thiol of its dithiol-functionalized surface. In the second (bottom left) FAD-functionalized Au-NPs are assembled on the electrode and reacted with apo-GOx. The direction of the flow of electrons from glucose to the gold electrode is shown by the arrows on the right. Holes (electron vacancies) flow in the reverse direction, from the electrode to glucose. B) TEM image of GOx reconstituted with the Au-FAD hybrid NP. Arrows show Au clusters. C) CVs corresponding to the bioelectrocatalyzed oxidation of glucose by the Au-NP-GOx electrode prepared according to route 1 (top left), in the presence 
of different glucose concentrations: (a) $0 \mathrm{mM}$, (b) $1 \mathrm{mM}$, (c) $10 \mathrm{mM}$, (d) $20 \mathrm{mM}$, and (e) 50 mM. Results were recorded in $0.1 \mathrm{M}$ phosphate buffer ( $\mathrm{pH} 7.0$ ), under Ar, potential scan rate 5 $\mathrm{mV} / \mathrm{s}$. Adapted with permission from [223] and [170]. Copyright 2003, Springer Nature and Science AAS

Figure 11. (left) Ribbon diagram of a GOx monomer (from A. niger) with the FAD molecule shown in blue. The amino acid residues targeted for mutagenesis are highlighted as space-filling models: cysteine (yellow), histidine (red-13.8 ̊), serine (purple-28.5 ^), alanine (orange-18.6 $\AA$ ), tyrosine (pink-22.2 ̊), and glutamate (light blue-15.3 $)$ ). The yellow sphere represents an idealized AuNP on the same scale as GOx.(right) Schematic drawing of the covalent-binding chemistry of cysteine to a maleimide-modified AuNP. The molecules are displayed as ball-andstick: carbon (gray), oxygen (red), nitrogen (blue), and sulfur (yellow). CVs of H447C_AuNP conjugates on a gold electrode in the presence (black line) and absence (gray line) of $1 \mathrm{M}$ glucose $\left(\mathrm{N}_{2-}\right.$ saturated buffer, $\left.\mathrm{pH} 7,10 \mathrm{mV} / \mathrm{s}\right)$. The $\mathrm{CV}$ for unconjugated $\mathrm{H} 44 \mathrm{C}$ is shown as a dotted line. The H447C_AuNP conjugates in the presence of glucose exhibit enzymatic glucose oxidation starting at ca. $400 \mathrm{mV}$. There is a 22 amino acids difference due to the peptide signal compared to reference[172]. Reprint with permission from[171]. Copyright 2012, The American Chemical Society

Figure 12. Correlation between the surface charge of GOx and the glucose oxidation current when GOxs are immobilized within osmium redox polymers. GOx from P. amagasakiense overexpressed either in E. coli $(132 \mathrm{kDa})$, in $P$. pastoris $(155 \mathrm{kDa})$, or overexpressed in $P$. pastoris and deglycosylated (139 kDa) and GOx from A. niger (158 kDa)

Figure 13: 3-D-structure of the engineered GOx from A. niger. Reprinted with permission from [94]. Copyright 2002, Elsevier 
Figure 14. Pymol generated images of the GOx from A. niger (A, PDB 1 gal) and from $P$. amagasakiense (B, PDB 1gpe). The arrows show the selected amino acid and their mutation. Reprint with permission from[104] Copyrigth 2013, John Wiley and Sons. These images were produced using PyMol 1.7.4.5 (Schrödinger, LLC., New York, NY, USA)

Figure 15: A) Schematic view of the mediator QDM-2 bound within the active site of GOx (left) with an enlarged view of the key amino acid residue Y414 (right). The mediator QDM binds in the active site in a location and at a distance that is suited for direct electron transfer

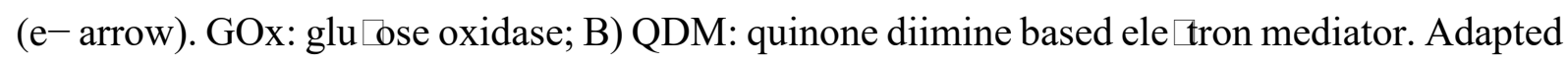
with permission from [186]. Copyright 2018, Wiley \& Sons.

Figure 16. Pymol generated images of GOx from A. niger (PDB: 1gal) showing the location of the mutation obtained by Holland et al.[172]. These images were produced using PyMol 1.7.4.5 (Schrödinger, LLC., New York, NY, USA)

Figure 17: Pymol generated images of GOx from A. niger (PDB: 1gal) showing the location of the mutation obtained by Schwaneberg's group.[90, 186-188, 210] These images were produced using PyMol 1.7.4.5 (Schrödinger, LLC., New York, NY, USA)

Figure 18: Preparation of $\mathrm{FADCl}_{2}$ - Glucose Oxidase. 1) chemical synthesis of 7,8-dichlororiboflavin; 2) production/purification of FAD-synthetase; 3) preparation of apo-FAD synthetase; 4) enzymatically synthesis of 7,8-dichloro-FAD; 5) preparation of apo-glucose oxidase; 6) reconstitution of glucose oxidase with 7,8-dichloro-FAD. Adapted with permission from[201]. Copyright 2014, The Royal Society of Chemistry 
Figure 19: Dependence of the normalized current density on the glucose concentration for electrodes modified with native GOx (triangles) and 7,8-dichloro-FAD-GOx (circles). Inset: Zoom in the $0-10 \mathrm{~mm}$ glucose concentration range. $35 \mathrm{wt} \%$ enzyme, $55 \mathrm{wt} \%$ redox polymer and $10 \mathrm{wt} \%$ of PEGDGE for a total dry loading of $200 \mu \mathrm{g} . \mathrm{cm}^{-2} .20 \mathrm{mM}$ phosphate buffer, 140 $\mathrm{mM} \mathrm{NaCl}, \mathrm{pH} \mathrm{7,} 37^{\circ} \mathrm{C}, 1000 \mathrm{rpm}$. Measured at $+0.3 \mathrm{~V}$ vs. $\mathrm{Ag} / \mathrm{AgCl}$. Adapted with permission from[201]. Copyright 2014, The Royal Society of Electrochemistry.

Figure 20: 3D structure of cholesterol oxidase from Streptomyces sp. (PDB ID: 1mxt) and oxygen- interacting structural models for glucose oxidases. The oxygen molecule (red ball) of 1mxt was superimposed on 1gpe and 1cf3. These images were produced using PyMol 1.7.4.5 (Schrödinger, LLC., New York, NY, USA). Reprinted with permission form [205]. Copyright 2012, MDPI

Figure 21. Calibration curves of the response of enzyme sensors constructed with wild-type GOx (squares) or the S114A/F355L mutant (circles). The correlation between current increase and substrate concentration under normal atmospheric conditions (filled symbols) or under argon (white symbols). Curves through the data points are the best fit obtained with an empirical Hill equation by using Graph-Pad Prism 5 software. All points represent averages of at least 5 readings, with coefficients of variation of less than 3\%. Reprinted with permission from [207]. Copyright 2014, Elsevier

Figure 22 A) Pymol generated images of GOx from P. Amagasakiense (PDB: 1gpe) with the location of the mutations obtained by Tremey et al.[209] B) Dependence of the normalized current density on the glucose concentration for electrodes made with native GOx (black triangles), K424E (green circles), V564S (red circles) and K424-V564S (blue squares). 35 wt\% enzyme, $55 \mathrm{wt} \%$ redox polymer and $10 \mathrm{wt} \%$ of PEGDGE for a total dry loading of $108 \mu \mathrm{g} . \mathrm{cm}^{-}$ 


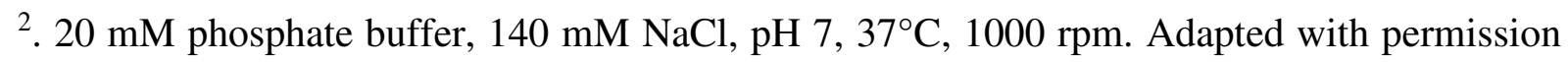
from[209]. Copyright 2017, John Wiley \& Sons. These images were produced using PyMol 1.7.4.5 (Schrödinger, LLC., New York, NY, USA).

Figure 23. Summary of the mutations performed to increase the electron transfer rate and/or decrease the $\mathrm{O}_{2}$ sensibility. Pymol generated images of GOx from P. Amagasakiense (PDB: 1gpe) and A. niger (PDB:1gal) Cyans: increase electron transfer and decrease $\mathrm{O}_{2}$ sensitivity; Yellow: increase electron transfer and increase $\mathrm{O}_{2}$ sensitivity; Gold: Decrease electron transfer and $\mathrm{O}_{2}$ sensitivity. These images were produced using PyMol 1.7.4.5 (Schrödinger, LLC., New York, NY, USA). 
